\title{
Seed and pollen dispersal distances in two African legume timber trees and their reproductive potential under selective logging
}

\author{
Olivier J. Hardy ${ }^{1}$ | Boris Delaide ${ }^{1}$ | Hélène Hainaut $^{1}$ | Jean-François Gillet ${ }^{2,3}$ | \\ Pauline Gillet $^{2}$ | Esra Kaymak ${ }^{1}$ | Nina Vankerckhove ${ }^{1}$ | Jérôme Duminil ${ }^{1,4,5}$ | \\ Jean-Louis Doucet ${ }^{2,6}$
}

\author{
${ }^{1}$ Evolutionary Biology and Ecology Unit, CP \\ 160/12, Faculté des Sciences, Université \\ Libre de Bruxelles, Brussels, Belgium \\ ${ }^{2}$ TERRA Teaching and Research \\ Centre, Forest is Life, Gembloux Agro-Bio \\ Tech, Université de Liège, Gembloux, \\ Belgium \\ ${ }^{3}$ Nature Forest Environment, Freelance in \\ Tropical Forestry, Porcheresse, Belgium \\ ${ }^{4}$ DIADE, IRD, Univ Montpellier, Montpellier, \\ France \\ ${ }^{5}$ Bioversity International, Forest Genetic \\ Resources and Restoration Programme, Sub- \\ Regional Office for Central Africa, Messa, \\ Yaoundé, Cameroon \\ ${ }^{6}$ Nature+ asbl, Wavre, Belgium \\ Correspondence \\ Olivier J. Hardy, Evolutionary Biology \\ and Ecology Unit, CP 160/12, Faculté des \\ Sciences, Université Libre de Bruxelles, \\ Av. F. D. Roosevelt 50, B-1050 Brussels, \\ Belgium. \\ Email: ohardy@ulb.ac.be \\ Funding information \\ F.R.S.-FNRS, Grant/Award Number: \\ X.3040.17; the Belgian Science \\ Policy (BELSPO), Grant/Award Number: \\ BR/132/A1/AFRIFORD; the Fonds Français \\ pour l'Environnement Mondial, Grant/Award \\ Number: CZZ1636.01D, CZZ1636.02D and \\ CZZ201.01R
}

\begin{abstract}
The natural regeneration of tree species depends on seed and pollen dispersal. To assess whether limited dispersal could be critical for the sustainability of selective logging practices, we performed parentage analyses in two Central African legume canopy species displaying contrasted floral and fruit traits: Distemonanthus benthamianus and Erythrophleum suaveolens. We also developed new tools linking forward dispersal kernels with backward migration rates to better characterize long-distance dispersal. Much longer pollen dispersal in D. benthamianus (mean distance $d_{p}=700 \mathrm{~m}$, $m_{p}=52 \%$ immigration rate in $6 \mathrm{~km}^{2}$ plot, $s=7 \%$ selfing rate) than in E. suaveolens $\left(d_{p}=294 \mathrm{~m}, m_{p}=22 \%\right.$ in $2 \mathrm{~km}^{2}$ plot, $\left.s=20 \%\right)$ might reflect different insect pollinators. At a local scale, secondary seed dispersal by vertebrates led to larger seed dispersal distances in the barochorous E. suaveolens $\left(d_{\mathrm{s}}=175 \mathrm{~m}\right)$ than in the wind-dispersed $D$. benthamianus $\left(d_{s}=71 \mathrm{~m}\right)$. Yet, seed dispersal appeared much more fat-tailed in the latter species ( $15 \%-25 \%$ seeds dispersing $>500 \mathrm{~m}$ ), putatively due to storm winds (papery pods). The reproductive success was correlated to trunk diameter in E. suaveolens and crown dominance in $D$. benthamianus. Contrary to $D$. benthamianus, E. suaveolens underwent significant assortative mating, increasing further the already high inbreeding of its juveniles due to selfing, which seems offset by strong inbreeding depression. To achieve sustainable exploitation, seed and pollen dispersal distances did not appear limiting, but the natural regeneration of $E$. suaveolens might become insufficient if all trees above the minimum legal cutting diameter were exploited. This highlights the importance of assessing the diameter structure of reproductive trees for logged species.
\end{abstract}

\section{KEYWORDS}

African rainforest, forestry, gene dispersal, mating system, parentage analysis, sustainable management 


\section{1 | INTRODUCTION}

Seed and pollen dispersal affects the dynamics of plant populations, their genetic structure and their response to selection pressures (e.g., García, Klein, Jordano, \& Rees, 2016). However, it is difficult to monitor directly the movements of seeds or pollen, especially the long-distance dispersal events which strongly impact the colonization dynamics of populations (Clark, Lewis, \& Horvath, 2001; Nathan, 2008). This constraint still limits our capacity to parameterize reliably models of population dynamics for most plant species. This is notably the case of tropical rainforest trees for which it is very difficult to study pollination and seed dispersal processes owing to sampling constraints (size of trees, irregular flowering, etc.). This knowledge gap hinders the sustainable management of tropical timber species. Gene dispersal affects the response to selection pressures, a key component of adaptive forest management (Lefèvre et al., 2014; Cavers \& Cottrell 2015). Seed and pollen dispersal patterns could also be critical for the natural regeneration after logging (e.g., Duminil et al., 2016, 2016; Tani et al., 2012; Wernsdörfer et al., 2011).

Selective logging in Central Africa typically harvests one or two trees per ha (all species confounded) in well-managed logging concessions, such as those certified by the Forest Stewardship Council (FSC). Harvesting is done every $25-30$ years (Ruiz Pérez et al., 2005) and must respect species-specific minimum cutting diameters (i.e., Legal Minimum Cutting Diameter, LMCD) which can vary among countries. At the concession level, a Management Minimum Cutting Diameter (MMCD) higher than the LMCD can be imposed by the management plan to fulfil legal requirements (in general to reach a recovery rate of at least $50 \%$ between rotations) (Doucet et al., 2016). In the context of selective logging, different processes can impact the natural regeneration of exploited tree species after logging (Figure 1). (a) The removal of adult trees is expected to lower the overall seed production. (b) Under limited pollen dispersal, the increased spacing between mature trees could limit cross-pollination, favouring selfing or other forms of inbreeding, and causing ovule abortion or generating low-quality seeds if inbreeding depression occurs (Duminil et al., 2016). (c) Under limited seed dispersal, the reduced density of mature trees could limit seed rains into sites suitable for seedling establishment. (d) Changes in local abiotic conditions (e.g., canopy openings, local soil compaction) could benefit or disadvantage the investment in reproductive organs, the establishment of seedlings and/or the growth of saplings, depending on species ecology (Swaine \& Agyeman, 2008). (e) Increased hunting and poaching (especially on large mammals) facilitated by the opening of new roads in remote areas can strongly affect seed dispersal of zoochorous species (Abernethy, Coad, Taylor, Lee, \& Maisels, 2013; Haurez, Petre, \& Doucet, 2013).

Different genetic approaches have enhanced our knowledge of dispersal processes. Among them, approaches based on the neighbourhood model allow estimating parameters of seed and/or pollen forward dispersal kernels (i.e., distribution of seed or pollen rains around parents) as well as backward seed and/or pollen migration rates from outside an exhaustively sampled area, the "neighbourhood" (e.g., Burczyk, Adams, Birkes, \& Chybicki, 2006; Chybicki, 2018; Klein, Desassis, \& Oddou-Muratorio, 2008). These likelihood or Bayesian approaches can also estimate selection gradients which describe the impact of individual traits on reproductive success.

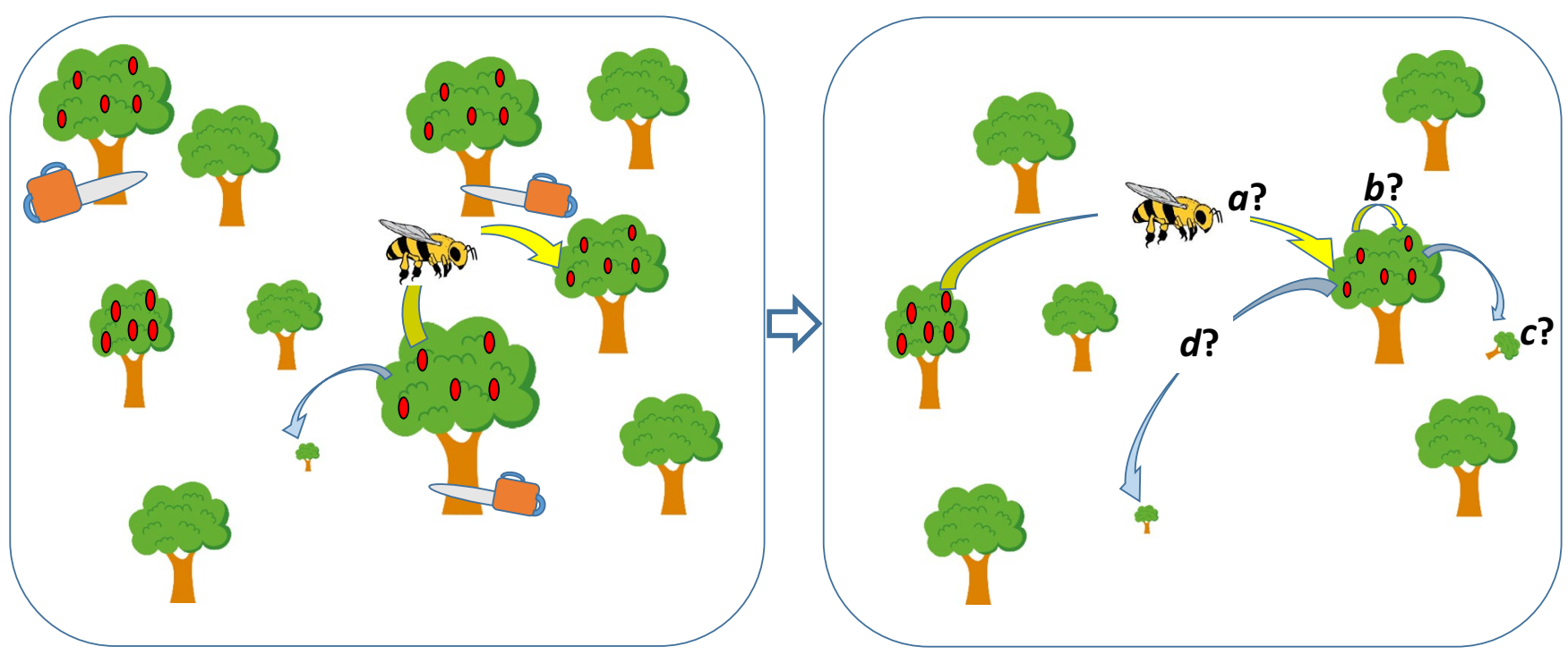

FIG URE 1 Selective logging in a natural population (left panel) reduces the density of adult trees (represented by fruits in their crown) and could affect their reproduction (right panel) depending on dispersal capacities (arrows). Under limited pollen dispersal, isolated reproductive trees could be less well pollinated (a), or more self-pollinated (b), resulting in higher seedling or sapling mortality under inbreeding depression (c). Under limited seed dispersal, potentially driven by increased hunting in logged areas for animal-dispersal trees, suitable sites for seedling establishment could be too far from fruiting trees to be under their seed rain (d). Postlogging environmental conditions could also impact regeneration, positively or negatively depending on the species ecology, by affecting the investment in reproductive organs or the probability of seedling establishment 
They are thus helpful to address the impact of the above-mentioned processes (a) to (c) on post-harvesting natural regeneration. A limit of currently available tools is that they do not assess whether estimated migration rates can be explained solely by the inferred dispersal kernels (but see Chybicki \& Oleksa, 2018). To bridge this gap, it is necessary to develop a method predicting backward migration rates from forward dispersal kernels given the distribution of individuals within and outside the neighbourhood. Finally, it is worth mentioning that combining fine-scale spatial genetic structure and paternity/parentage analyses allows detecting assortative mating, that is, when mating adults are more related than expected by chance after accounting for limited pollen dispersal, a pattern found in an African timber tree (Monthe, Hardy, Doucet, Loo, \& Duminil, 2017). However, we lack data to assess the prevalence of assortative mating in tropical trees despite its contribution to inbreeding.

In tropical rainforest trees, genetic methods have revealed that seeds often disperse more locally than pollen which can move several kilometres away (see review of Ashley, 2010; Dick, Hardy, Jones, $\&$ Petit, 2008). Nevertheless, most studies could hardly monitor or estimate long-distance dispersal events, except for populations at low density in highly fragmented habitats (e.g., Finger et al., 2012; Ismail et al., 2017; Lander, Bebber, Choy, Harris, \& Boshier, 2011). Moreover, there is substantial variation among species according to their specific pollination or seed dispersal syndromes (e.g., Kettle et al., 2011; Tani et al., 2012). Here, considering two timber species exploited in Central Africa and displaying contrasted flower and fruit characters, we seek to characterize their seed and pollen dispersal capacities as well as the determinants of their reproductive success, and to assess whether these parameters could be limiting factors for their natural regeneration in the context of selective logging in unfragmented forests.

Distemonanthus benthamianus Baillon and Erythrophleum suaveolens (Guill. et Perr.) Brenan are two legume timber trees of similar size (height up to $40 \mathrm{~m}$ and diameter at breast height, dbh, up to c. 130$150 \mathrm{~cm}$ ) showing a similar ecology in Central African moist forests. Previous works based on the spatial genetic structure of populations suggested comparable gene dispersal distances: 400 to $1,000 \mathrm{~m}$ in D. benthamianus (Debout, Doucet, \& Hardy, 2011) and from 400 to $500 \mathrm{~m}$ in E. suaveolens (Duminil et al., 2016). However, the relative contributions of seed and pollen to these estimates were unknown. Both species are light-demanding and long-living terra firme canopy trees, producing bisexual flowers and pods with dormant seeds, but they differ by some important reproductive traits that can affect their respective seed and pollen dispersal abilities.

Regarding pollen dispersal, while $D$. benthamianus has relatively showy, slightly zygomorphic, white flowers of medium size (petals 1-1.5 cm), E. suaveolens bears small (petals 2-3 mm long) whitish to pale green-yellowish flowers assembled in spike-like racemes up to $12 \mathrm{~cm}$ long (Figure 2). The flowers of $D$. benthamianus are expected to attract relatively large insects (e.g., bees), while the small flowers of E. suaveolens could attract smaller insects. Positive correlations between flower size, pollinator size and pollen dispersal distance were reported in Asian Dipterocarps (Kettle et al., 2011), so that we hypothesize that pollen could be dispersed on larger distances in $D$. benthamianus than in E. suaveolens.

Regarding seed dispersal, D. benthamianus produces thin-walled, flattened elliptical, 2 - to 5 -seeded indehiscent pods $(7-13 \times 2.5$ $3.5 \mathrm{~cm}$ ) dispersed by wind (Aubréville, 1968), while E. suaveolens
FIGURE 2 Flowers and fruits of Distemonanthus benthamianus (above: flower and indehiscent pod) and Erythrophleum suaveolens (below: inflorescence with a look up at flowers and closed and open dehiscent pods with six seeds covered by a mucilage). The bars on the upper-left corners are $1 \mathrm{~cm}$ scales. Pictures by $\mathrm{O}$. Hardy and J.-L. Doucet, except flower of $D$. benthamianus by $\mathrm{X}$. van der Burgt (C)

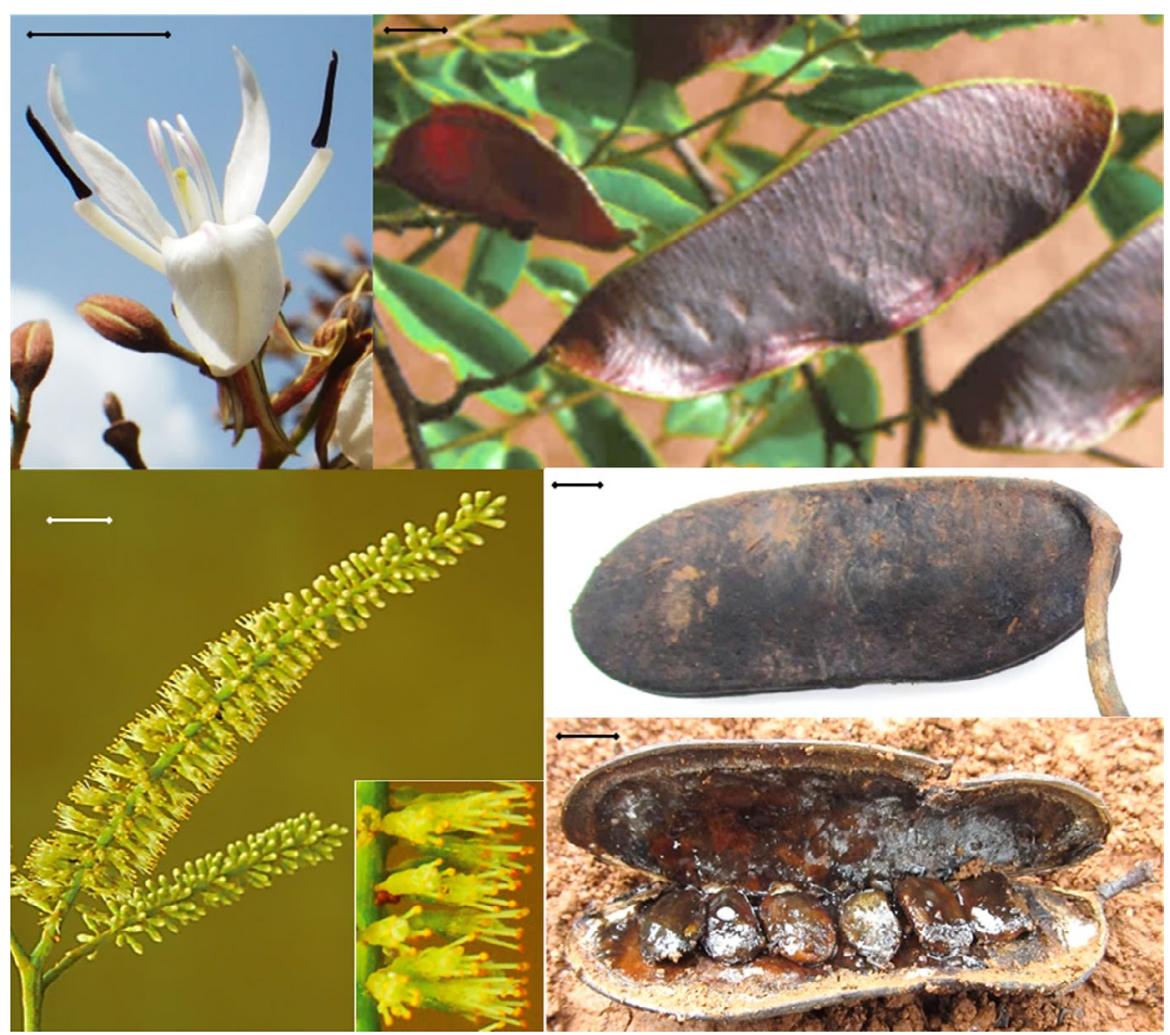


produces heavier, flat and slightly curved 6- to 11-seeded dehiscent pods $(5-17 \times 3-5 \mathrm{~cm})$ with seeds dispersed by gravity (most of the seeds remain attached in the pods after their opening) (Figure 2). Seed dispersal is expected to be only driven by wind dispersal of pods in $D$. benthamianus (monkeys eat only immature pods and, to our knowledge, intact seeds have never been reported in animal faeces; Gautier-Hion, Gautier, \& Maisels, 1993; Poulsen, Clark, Connor, \& Smith, 2002). Direct observations suggested pod dispersal distances up to $50 \mathrm{~m}$ (Hecketsweiler, 1992), but occasional storm winds might cause long-distance dispersal (Maurer, Bohrer, Medvigy, Wright, \& Thompson, 2013; Nathan et al., 2011). Erythrophleum suaveolens pods are too heavy to be dispersed by wind, but their seeds can benefit secondary dispersal through endozoochory (Guion, 2011) by rodents or primates (Poulsen, Clark, \& Smith, 2001), and intact seeds have sometimes been found in the faeces of gorilla, Gorilla gorilla (Petre et al., 2015) or in the rumen of duikers, Cephalophus spp (F. Houngbégnon and J.-L. Doucet, unpublished). Hence, the relative efficiency of seed dispersal in D. benthamianus and E. suaveolens should depend on the respective impacts of wind dispersal versus zoochorous secondary dispersal. We also expect that wind dispersal is more likely to result in anisotropic dispersal kernel than animal dispersal.

Here, using nuclear microsatellite markers (nSSR), we compared seed and pollen dispersal of $D$. benthamianus and $E$. suaveolens in unfragmented forests of Central Africa, where the frugivorous fauna is relatively intact (Tosso et al., 2017), to address the following questions. (a) What are the patterns of seed and pollen dispersal in each species (mean dispersal distances, shape of the dispersal kernels, immigration rates, anisotropy, assortative mating) and are differences between species related to different dispersal syndromes? (b) Are seed and pollen migration rates correctly predicted by the estimated dispersal kernels, or do the later under or overestimate long-distance dispersal? (c) Are there signs of inbreeding depression and/or assortative mating? (d) Are individual male and/or female reproductive successes related to the diameter of the trunk or the dominance of crown in the canopy? These new biological data will then be discussed in the context of sustainable exploitation to assess whether natural regeneration after logging could be affected by (a) limited pollen dispersal or assortative mating combined with inbreeding depression, (b) limited seed dispersal, (c) the reduction in population reproductive potential expected if all trees above the minimum cutting diameter were exploited.

\section{2 | MATERIALS AND METHODS}

\section{1 | Study species}

Distemonanthus benthamianus and Erythrophleum suaveolens are legume trees from subfamilies Dialioideae and Caesalpinioideae, respectively (LPWG, 2017). Both are logged timber species in West and Central Africa, and among the ten most cut in Cameroon and Gabon, where their Legal Minimum Cutting Diameter (LDMC) reach 50 and $70 \mathrm{~cm}$, respectively (de Wasseige, Flynn, Louppe, Hiol Hiol, \& Mayaux, 2014). They both show a regeneration deficit in closed-canopy forests (bell-shaped population structure typical of old stand of light-demanding species in closed-canopy forest; Morin-Rivat et al., 2017; Ouédraogo et al., 2018), where they can be locally relatively abundant (1-2 trees with $\mathrm{dbh}>30 \mathrm{~cm}$ per ha). They produce flowers from a dbh of $20 \mathrm{~cm}$ (D. benthamianus, Doucet, 2003) or $30 \mathrm{~cm}$ (E. suaveolens; Kouadio, 2009), but mature fruits are only observed when the $\mathrm{dbh}>40 \mathrm{~cm}$ (Doucet, 2003). (a)

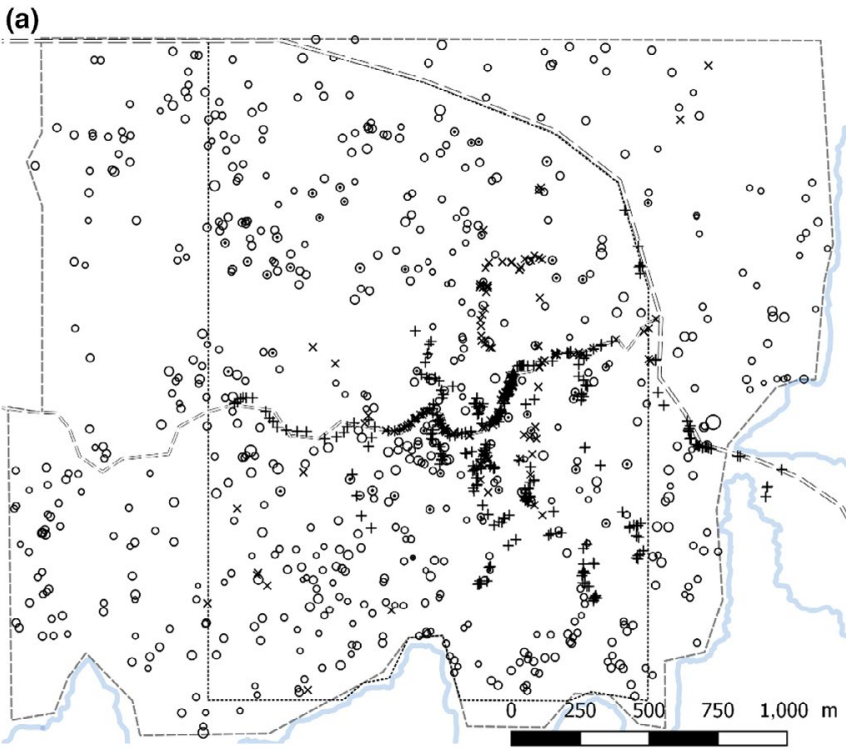

(b)

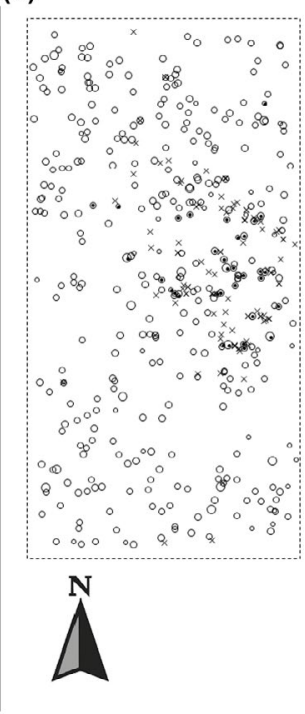

FIGURE 3 Sampled populations of (a) Distemonanthus benthamianus in central Gabon and (b) Erythrophleum suaveolens in south-east Cameroon (same scale). Circles indicate sampled trees, their diameter reflecting their $\mathrm{dbh}$. Circles with a dot inside indicate trees below which seeds were collected and genotyped. Symbols $x$ and + indicate seedlings sampled before and after logging, respectively. The stippled lines delimit the prospected areas. For D. benthamianus, the inner and outer areas were sampled for all trees from 20 and $50 \mathrm{~cm} d b h$, respectively. Doubled stippled lines indicate road (wide) or ancient skid trails (narrow), while the grey continuous line indicates the course of a river. For E. suaveolens, all trees from $20 \mathrm{~cm}$ dbh were sampled 


\subsection{Study sites and sampling}

Distemonanthus benthamianus and E. suaveolens were respectively sampled in an evergreen forest from eastern Gabon and a semi-evergreen forest from eastern Cameroon. These forests are located in areas of low human population density. They are logged under the framework of the FSC and logging companies implement antipoaching activities.

Distemonanthus benthamianus was studied in the Forest Management Unit "UFA1-UFG3" managed by "Precious Woods Gabon-Compagnie Equatoriale des Bois S.A. company" (CEB hereafter), in the Annual Allowable Cut 2010-Bambidie. This area had been selectively logged more than 25 years ago but presented a closed-canopy structure, typical of an old-growth evergreen forest, at the time of our sampling in 2009-2010. Though we lack details on past logging operations, we can assume that $D$. benthamianus was never exploited in this area (CEB, pers. comm.). We concentrated our sampling in a $3.45 \mathrm{~km}^{2}$ area centred around $0.82^{\circ} \mathrm{S}, 13.07^{\circ} \mathrm{E}$ (Figure 3a). We sampled few $\mathrm{cm}^{2}$ of cambium for all trees of $D$. benthamianus above $20 \mathrm{~cm}$ dbh in October 2009 and March 2010 (394 trees sampled, density $114 \mathrm{ind} / \mathrm{km}^{2}$ ). We further enlarged the sampling area to $6.56 \mathrm{~km}^{2}$ around the exhaustive sampling area by collecting only the trees already inventoried by CEB for an exploitation inventory (>50 cm dbh). For each tree sampled, we took GPS coordinates (c. 5-15 $\mathrm{m}$ precision), estimated the dbh class (10 cm classes) and assessed the dominance in three classes, that is, whether the crown of the tree was below, within or above the canopy layer of surrounding trees. We also collected seeds below the crown of sampled trees when available, and seedlings when we encountered them (usually in openings). To assess the impact of a logging phase that occurred in 2011, where only 26 trees from the $6.56 \mathrm{~km}^{2}$ sampling area were logged (i.e., $4.3 \%$ of the 611 trees sampled, or $17.6 \%$ of the trees above the MMCD of $70 \mathrm{~cm}$ ), we collected 278 seedlings throughout the area in 2017 (Figure 3). We expect that most of these seedlings were recruited after logging, $97 \%$ having a stem $<2.5 \mathrm{~cm}$ diameter at their base, while seedlings of $D$. benthamianus are known to grow fast (up to $1 \mathrm{~cm} /$ year, Doucet et al., 2016).

Erythrophleum suaveolens was studied in the Forest Management Unit "UFA10-030" managed by "Pallisco" company, in the Annual Allowable Cut 11. This area presents a semi-evergreen old-growth closed-canopy forest. It has never been logged. Our study area was a $2 \mathrm{~km}^{2}$ plot (Figure $3 \mathrm{~b}$ ) centred around $2.86^{\circ} \mathrm{N}, 13.77^{\circ} \mathrm{E}$ (DynAfFor project, https://www.dynaffor.org). We sampled all E. suaveolens trees with a dbh $>20 \mathrm{~cm}$ in 2013 (357 adults sampled, density of 178 stems $/ \mathrm{km}^{2}$ ), as well as seeds and seedlings following the same protocol as for $D$. benthamianus, and considered in addition 62 seedlings and seeds from 34 mother trees collected in 2012 for a pilot study (Duminil et al., 2016).

Missed, nonsampled adults can lead to an overestimation of the actual immigration rates so that we estimated the exhaustiveness of our adult sampling. In the $D$. benthamianus population, we relied on a CEB logging inventory to check the proportion of these trees that we recovered in our $3.45 \mathrm{~km}^{2}$ "exhaustive sampling" (spatial position and dbh were used to match the trees of our respective inventories). In the E. suaveolens population, we relied on the sampling of 47 trees in our study area one year before our inventory (Duminil et al., 2016) to estimate the proportion recovered in our inventory (spatial position, $\mathrm{dbh}$ and genotypes were here used to match trees).

\section{3 | Microsatellite genotyping}

DNA was extracted using the NucleoSpin plant kit (MachereyNagel, Deuren, Germany). Samples of D. benthamianus (610 adults, $190+278$ seedlings and 388 seeds below 46 putative mother trees) were genotyped at 12 nSSR loci (Debout et al., 2011; Demenou, Piñeiro, \& Hardy, 2016). Samples of E. suaveolens (357 adults, 109 seedlings and 307 seeds below 26 putative mother trees) were genotyped at nine nSSR loci following Duminil et al. (2011). To estimate the genotyping error rates, $40 \mathrm{E}$. suaveolens and $72 \mathrm{D}$. benthamianus samples were genotyped twice.

\subsection{Data analyses}

\subsection{1 | Markers polymorphism, inbreeding, null alleles and indirect selfing rate estimation}

Allelic richness, observed $\left(H_{0}\right)$ and expected $\left(H_{e}\right)$ heterozygosities, inbreeding coefficient $\left(F=1-H_{o} / H_{e}\right)$ and the selfing rate were estimated in each population separately for adults, seedlings and seeds using SPAGEDI ver. $1.5 \mathrm{~d}$ (Hardy \& Vekemans, 2002). Selfing rates were estimated indirectly from the degree of identity disequilibrium between loci, a robust method to the presence of null alleles (David, Pujol, Viard, Castella, \& Goudet, 2007). As apparent heterozygote deficit can result from the occurrence of null alleles, we also jointly estimated true inbreeding coefficient $F$ and null allele frequencies under the inbreeding population model using INEST ver. 1.1 (Chybicki \& Burczyk, 2009). $H_{o}$ estimates were compared between seeds, seedlings and adults to assess whether there are signs of inbreeding depression reducing observed heterozygosity with age.

\subsection{2 | Identification of dispersed and nondispersed seeds}

As seeds were collected below trees, we first checked for each seed whether the overhang tree was indeed the mother, following a method similar to Hampe, Masri, and Petit (2010) but based on LOD scores rather than parentage exclusion. To this end, we used CERvus ver. 3.0 (Marshall, Slate, Kruuk, \& Pemberton, 1998) to compute the LOD score of each pair of seed and overhang tree using the equation of Kalinowski, Taper, and Marshall (2007), with rates of mistyped loci of 0.05 and 0.03 for D. benthamianus and E. suaveolens, respectively, as estimated from replicated genotypes (see results2.1). We then simulated as many progeny genotypes as sampled seeds for each overhang tree by picking for each locus one allele from the mother tree and one allele sampled in proportion to the observed allele frequencies. We further added genotyping errors to both the mother 
genotypes and to the simulated progeny genotypes, at rates equal to the estimated typing error rates per locus, and added missing values in proportion to those seen in actual seed genotypes and computed LOD scores for each pair of simulated progeny and mother genotypes as well as each pair of simulated progeny and nonmother genotypes. From these distributions, we estimated the minimal LOD score $\left(\operatorname{LOD}_{\min }\right)$ above which $99 \%$ of the simulated progeny-mother LOD scores occur, and the maximal LOD score ( LOD $_{\text {max }}$ ) below which $99 \%$ of the simulated progeny-nonmother LOD scores occur (Figure S1). These thresholds allowed us to categorize seeds in three categories: (a) seeds for which the overhang tree is assumed to be the mother tree because their LOD score $>$ LOD $_{\text {max }}$, (b) seeds for which the overhang tree may be the mother but there is a risk that another tree is the actual mother because LOD $_{\text {min }}<$ LOD score $<$ LOD $_{\max }$ and (c) seeds for which the overhang tree is not the mother because their LOD score $<\mathrm{LOD}_{\min }$. It should be noted that this procedure differs from the simulation algorithm implemented in Cervus which was conceived to test parentage of a defined number of candidate parents considered a priori as likely, while here we tested a single candidate parent, the overhang tree. For seeds of category (c), we further checked whether an adult tree situated at $<100 \mathrm{~m}$ could be a parent, and assumed it was the mother if it was the only tree with a LOD score with the seed $>L_{\text {OOX }}$.

\subsection{3 | Estimation of seed and pollen dispersal parameters and selection gradients}

We relied on the neighbourhood model implemented in the software $\mathrm{NM} \pi$ (Chybicki, 2018) to model the forward seed and pollen dispersal kernels by a maximum-likelihood approach accounting simultaneously for genotypic and spatial data of adults, seeds and seedlings, as well as adult traits. Here, we assigned seeds incompatible with the overhang tree (category 3 ) to the "dispersed progeny" category (together with seedlings) and seeds compatible with the overhang tree (category 1) to the "nondispersed progeny" category. Seeds for which the maternity of the overhang tree remained ambiguous (category 2) were either included in the data set (and considered as nondispersed), or they were removed from the data set to assess whether they affect significantly the estimation of parameters. For $D$. benthamianus, we also contrasted estimates based on seedlings sampled before or after logging. Pollen and seed dispersal were summarized by: (a) the selfing rate, $s_{0}$; (b) the pollen and seed immigration rates, $m_{p}$ and $m_{s}$, indicating the proportions of seeds and seedlings sired or mothered by nonsampled adults (i.e., parents situated outside of the sampled areas or inside the sampled areas but missed during the sampling); and (c) four parameters of the exponential-power-von Misses distribution (an extension of the exponential-power distribution allowing anisotropy) for modelling the pollen and seed dispersal kernels. These kernel parameters were as follows: (a) the reciprocal of the mean pollen and seed dispersal distances, $d_{\mathrm{p}}$ and $d_{\mathrm{s}}$; (b) the exponents, $b_{\mathrm{p}}$ and $b_{\mathrm{s}}$, controlling the shape of the distributions (i.e., $b=2$ for a Gaussian distribution, $b=1$ for an exponential distribution, $b<1$ for a fattailed distribution); (c) the extent of anisotropy, $k_{p}$ and $k_{s}(k=0$ under isotropic dispersal); and (d) the azimuths of the prevailing pollen and seed dispersal directions, $a_{\mathrm{p}}$ and $a_{\mathrm{s}}$ (when $k_{\mathrm{p}}>0$ or $k_{\mathrm{s}}>0$ ). Traits of adult trees consisted in centred and standardized $\mathrm{dbh}$ values and canopy dominance values (raw dominance of 0,1 or 2 for trees with a crown below, at the same height or above the crowns of the highest adjacent trees, respectively). NM $\pi$ estimated how these traits affected the male and female reproductive successes of individual trees (selection gradients). From the occasional parent-progeny genotypic mismatches occurring in the data, NM $\pi$ also provided estimates of genotyping error rates per locus, which were compared to the estimates obtained by our genotyping replicates.

Once all parameters were estimated, $N M \pi$ provided the most likely mother and father of each seed and seedling with an associated probability, accounting simultaneously for the spatial, genotypic and trait data. Considering cases where parents were inferred with a probability $\geq 0.8$, we compared the distributions of $\mathrm{dbh}$ and crown dominance between all adults, inferred mothers and inferred fathers. We also plotted the relative position of dispersed seeds and seedlings with respect to their mother to illustrate seed dispersal and of mothers with respect to fathers to illustrate pollen dispersal.

\subsection{4 | Forward dispersal kernels versus backward migration rates-modelling the contribution of nonsampled trees to reproduction}

To investigate whether the estimated seed and pollen dispersal kernels and degrees of sampling exhaustiveness could predict pollen and seed migration rates, we wrote an R script (R Core Team 2017) to simulate the contribution of nonsampled trees to reproduction (Appendix S1). Our simulation approach differs from that of Chybicki and Oleksa (2018) who estimated emigration rates out of the sample area, assuming they were equal to the immigration rates, an assumption valid only under particular conditions (tree distribution following a random point process of constant density, random sampling of seeds/seedlings). Here we directly simulated seed and pollen coming from nonsampled trees. The algorithm (a) simulated missing adults within the sampling areas (according to the sampling exhaustiveness) and outside the sampling areas (using a 20-km-wide border surrounding the sampling areas and assuming a constant tree density) using random $\mathrm{X}, \mathrm{Y}$ coordinates, attributing trait values distributed as observed among the sampled adults; (b) computed for each sampled adult the expected proportions of fertilizing pollen originating from simulated versus sampled adults given the pollen dispersal kernel parameters, trait values and selection gradient parameters estimated by $\mathrm{NM} \pi$ (following eq. (2) to (4) in Chybicki, 2018); and (c) computed for the position of each sampled dispersed seed and seedling the expected proportions of seeds originating from simulated versus sampled adults (given the estimated seed dispersal kernel parameters) as well as the expected proportions of these seeds fertilized by simulated versus sampled adults. After averaging over all sampled progeny, the expected proportions of offspring mothered and/or sired by simulated adults were compared to the estimated seed and pollen migration rates. Computations were repeated five times, redrawing independently missing adults. 


\subsection{5 | Fine-scale spatial genetic structure of adults and assortative mating}

The spatial genetic structure of each species within the sampled plots was characterized by the decay of the kinship coefficient, $F_{i j}$, between adults with spatial distance (kinship-distance curve), following Vekemans and Hardy (2004). We used SPAGEDI ver. 1.5d (Hardy \& Vekemans, 2002) to compute $F_{\mathrm{ij}}$ using J. Nason's estimator (Loiselle, Sork, Nason, \& Graham, 1995) and averaged them for a set of nonoverlapping distance intervals to visualize the $F(r)$ curve. We permuted 5,000 times the spatial positions of the adults to draw $95 \%$ confidence intervals of the $F(r)$ curves under the null hypothesis (no genetic structure).

Assortative mating occurs when mates are more related to each other than expected by chance, after accounting for limited pollen dispersal distances (Monthe et al., 2017). Considering only outcrossed offspring where the two parents were identified with a probability $\geq 0.8$, we computed the $F_{\mathrm{ij}}$ between these mates and compared it with $F(r)$ where $r$ is the distance interval between the mates (i.e., the mean kinship coefficient between adults separated by the same spatial distance as the inferred mates). For each species, a t test for paired samples was used to assess whether the actual $F_{i j}$ between mates differed significantly from the values predicted from their spatial distance.

\section{3 | RESULTS}

\section{1 | Exhaustiveness of sampling}

In the $3.45 \mathrm{~km}^{2}$ area where we "exhaustively" sampled Distemonanthus benthamianus trees, CEB had previously inventoried 115 trees with a dbh $>70 \mathrm{~cm}$. Only five of these 115 trees (4.3\%) did not match any of the trees we had sampled independently. Hence, our sampling was at least $95 \%$ exhaustive (possibly more if species misidentification or miscoding occurred in the CEB database and explained why some trees were not found in our inventory). In the surrounding area where we focused on trees previously mapped by CEB (which neglected the smallest dbh), a comparison of the dbh distribution with that found in the "exhaustively" sampled areas lead us estimate that c. $80 \%$ of stems $>20 \mathrm{~cm}$ dbh had been sampled.

In the $2 \mathrm{~km}^{2}$ Erythrophleum suaveolens population, of the 47 trees collected in 2012, 41 were recovered in our 2013 inventory. Hence, we estimate that our sampling was c. $87 \%$ exhaustive. The distinctive orange-red bark of $D$. benthamianus, compared to the dark brown bark of $E$. suaveolens, probably explains a better detection of the former during our inventories.

\section{2 | Markers polymorphism, genotyping error rates, null alleles, inbreeding and selfing rates}

The 11 loci of $D$. benthamianus had 4 to 19 alleles (mean of 10.5) and a mean gene diversity of $H_{e}=0.56$ (Table S1). A weak multilocus heterozygote deficit (mean $F=0.15$ ) was mostly driven by one locus (dis130) which had a null allele at a frequency of 0.24. After accounting for null alleles, a weak inbreeding remained in adults $(F=0.059, S E=0.028)$. Genotyping error rates based on 72 replicates ranged from $1 \%$ to $11 \%$ (mean $5 \%$ ) per allele according to locus.

The 9 loci of E. suaveolens had fewer alleles (3 to 14, mean of 7.9) but a slightly higher mean gene diversity $\left(H_{e}=0.61\right)$. Heterozygote deficit (mean $F=0.17$ ) was driven by five loci displaying null alleles at frequencies ranging from $6 \%$ to $15 \%$. The inbreeding became nonsignificant in adults once null alleles were accounted for $(F=0.003$, $S E=0.008$ ). Genotyping error rates based on 40 replicates ranged from $0 \%$ to $7 \%$ (mean 3\%, Table S1).

The observed heterozygosity $\left(H_{0}\right)$ did not differ significantly among cohorts in $D$. benthamianus $H_{o}=0.48,0.50$ and 0.47 in seeds, seedlings and adults, respectively), while it increased with age in E. suaveolens $\left(H_{o}=0.47,0.47,0.51\right.$ in seeds, seedlings and adults, respectively; differences statistically significant between adults and seeds or seedlings, Duminil et al., 2016). The indirect selfing rate estimates in seeds, seedlings and adults reached, respectively, $0.046 \pm 0.067,0 \pm 0$ and $0.092 \pm 0.039$ in D. benthamianus, and $0.190 \pm 0.040,0.055 \pm 0.127$ and $0.000 \pm 0.016$ in E. suaveolens, confirming the apparent elimination of selfed and inbred individuals with age in the latter species (inbreeding depression).

\subsection{Assignment of seeds sampled below trees}

Of the 386 D. benthamianus and 307 E. suaveolens seeds sampled, respectively, 266 (69\%) and 111 (36\%) had sufficiently high LOD score with the overhang tree to conclude that the latter was the mother tree (nondispersed seeds; Figure S1). Respectively, 79 (20\%) and 58 (19\%) seeds had intermediate LOD scores with the overhang tree so that maternity remained ambiguous. Finally, 41 (11\%) D. benthamianus seeds and 138 (45\%) E. suaveolens seeds were clearly incompatible with the overhang tree and must have been dispersed beyond the crown of their mother tree. Among these dispersed seeds, we identified a very likely parent at $<100 \mathrm{~m}$ of the overhang tree for, respectively, 19 (46\%) and 39 (28\%) seeds which were therefore assigned to a mother tree. Altogether, we considered that we identified with high confidence the mothers of 285 (74\%) D. benthamianus and 150 (49\%) E. suaveolens seeds, and with limited confidence additional sets of $79(20 \%)$ and $58(19 \%)$ seeds, respectively.

\subsection{Seed and pollen dispersal modelling}

First (data sets 1 ), $N M \pi$ was run using the genotypes of: (a) all adults ( $N=611$ and 357, respectively, for $D$. benthamianus and $E$. suaveolens); (b) nondispersed seeds for which the overhang tree is not rejected as a possible parent ( $N=345$ and 169); (c) dispersed seeds for which a nonoverhang tree was identified as a very likely parent ( $N=19$ and 39), declared as dispersed seeds with known mother (but with the spatial coordinates of the overhang tree); and finally (d) seedlings sampled before logging ( $N=190$ and 109) as well as dispersed seeds incompatible with the overhang tree and for which no parent was identified within $100 \mathrm{~m}(\mathrm{~N}=22$ and 99), both declared as dispersed seeds of unknown maternity. To evaluate the 
robustness of our results, we also ran $\mathrm{NM} \pi$ on several modified data sets. In data sets 2 , we removed nondispersed seeds of category 2 , for which the overhang tree is compatible as a parent but not unambiguously a parent, because parent-offspring mismatches can affect the genotyping error rate estimates. In data set 3 of E. suaveolens, we also removed all 138 dispersed seeds to estimate seed dispersal parameters based on established seedlings only. In data set 3 of $D$. benthamianus, we used only the adults and the 278 seedlings sampled 6 years after logging. Hereafter, we describe results from data set 1 , just mentioning when results using data sets 2 or 3 differed substantially (Table S2).

Single-locus error rates estimated by $\mathrm{NM} \pi$ ranged from 0.5 to $7.7 \%$ (mean 2.6\%) in D. benthamianus and from 0 to $10.3 \%$ (mean $4.2 \%$ ) in E. suaveolens. They were well correlated to error rates estimated by genotyping replicates: $r=0.59$ for $D$. benthamianus and $r=0.80$ for E. suaveolens. After excluding seeds of category 2 (data sets 2 ), estimated error rates decreased but not dramatically, ranging from $0.3 \%$ to $6.0 \%$ (mean $2.3 \%$ ) in $D$. benthamianus and from 0 to $7.4 \%$ (mean $3.5 \%$ ) in E. suaveolens.

Pollen dispersal showed sharp contrasts between species (Table 1, Figure 4c,d). First, the selfing rate of offspring was much lower in $D$. benthamianus $\left(s_{0}=6.5 \%\right)$ than in E. suaveolens $\left(s_{0}=19.8 \%\right.$ ). Second, the pollen immigration rate was larger in $D$. benthamianus (mean $\pm S E: m_{p}=52 \% \pm 4 \%$ ) than in $E$. suaveolens $\left(m_{p}=22 \% \pm 4 \%\right)$, despite the fact that the sampled area was considerably smaller for the latter species (Table 1; Figure 3b). Third, forward pollen dispersal distance according to the fitted kernel was much larger in D. benthamianus, with a mean $d_{\mathrm{p}}=699 \mathrm{~m}[95 \%$ confidence interval: 409-2,412 m] and a fat-tailed distribution (exponent $b_{p}=0.40 \pm 0.12$ ), than in E. suaveolens, with a mean $d_{p}=294 \mathrm{~m}$ [239-383 m] and a kernel which did not differ significantly from an exponential distribution $\left(b_{p}=1.3 \pm 0.3\right)$. No evidence of pollen dispersal anisotropy was detected in $D$. benthamianus $\left(k_{p}=0.15 \pm 0.15\right)$, while in E. suaveolens pollen tended to disperse anisotropically $\left(k_{p}=0.57 \pm 0.18\right)$ with a prevailing southwest direction $\left(a_{\mathrm{p}}=235^{\circ} \pm 16^{\circ}\right)$.

Estimated seed dispersal parameters also varied strongly between species (Table 1, Figure 4a,b). Seed immigration rates were around $m_{s}=30 \% \pm 4 \%$ in $D$. benthamianus and $m_{s}=17 \% \pm 4 \%$ in E. suaveolens. Forward seed dispersal kernels were close to an exponential in both species but with much smaller mean dispersal distance in $D$. benthamianus $\left(d_{\mathrm{s}}=71 \mathrm{~m}\right.$ with $95 \% \mathrm{Cl}$ from 56 to $94 \mathrm{~m}$ and exponent $\left.b_{\mathrm{s}}=0.96 \pm 0.15\right)$ than in E. suaveolens $\left(d_{\mathrm{s}}=175 \mathrm{~m}\right.$ with $95 \% \mathrm{Cl}$ from 143 to $224 \mathrm{~m}, b_{\mathrm{s}}=0.93 \pm 0.11$ ). Dispersal anisotropy was not detected in E. suaveolens ( $k_{s}=0.04 \pm 0.15$; Figure $\left.4 b\right)$, while it was strong in $D$. benthamianus $\left(k_{p}=1.57 \pm 0.24\right)$ with a prevailing dispersal direction towards the West $\left(a_{\mathrm{s}}=258^{\circ} \pm 7^{\circ}\right.$; Figure 4a).

These results remained robust to the exclusion of seeds of category 2 (data sets 2): the most important changes were slight increases in estimates of selfing rates $(+1.3 \%$ in $D$. benthamianus and $+2.5 \%$ in E. suaveolens), pollen migration rates (no change in

\begin{tabular}{|c|c|c|}
\hline & $\begin{array}{l}\text { Distemonanthus } \\
\text { benthamianus }\end{array}$ & Erythrophleum suaveolens \\
\hline Selfing rate for adult cohort $\left(s_{a}\right)$ & $0.091 \pm 0.039$ & $0.000 \pm 0.013$ \\
\hline $\begin{array}{l}\text { Selfing rate for seed and seedling } \\
\text { cohort }\left(s_{0}\right)\end{array}$ & $0.065 \pm 0.013$ & $0.198 \pm 0.024$ \\
\hline Pollen immigration rate $\left(m_{p}\right)$ & $0.52 \pm 0.04$ & $0.22 \pm 0.04$ \\
\hline $\begin{array}{l}\text { Shape of pollen dispersal kernel } \\
\left(b_{p}\right)\end{array}$ & $0.40 \pm 0.12$ & $1.30 \pm 0.31$ \\
\hline $\begin{array}{l}\text { Mean kernel pollen dispersal } \\
\text { distance }\left(d_{p}\right)\end{array}$ & 699 m [409-2,412] & 294 m [239-383] \\
\hline Pollen dispersal anisotropy $\left(k_{p}\right)$ & $0.15 \pm 0.15$ & $0.57 \pm 0.18$ \\
\hline $\begin{array}{l}\text { Pollen dispersal prevailing direc- } \\
\text { tion }\left(a_{p}\right)\end{array}$ & / & $0.65 \pm 0.06(\mathrm{SW})$ \\
\hline Effect of dbh on male fitness & $0.03 \pm 0.11$ & $0.23 \pm 0.12$ \\
\hline $\begin{array}{l}\text { Effect of crown dominance on } \\
\text { male fitness }\end{array}$ & $0.63 \pm 0.15$ & $-0.09 \pm 0.13$ \\
\hline Seed immigration rate $\left(m_{s}\right)$ & $0.30 \pm 0.04$ & $0.17 \pm 0.04$ \\
\hline Shape of seed dispersal kernel $\left(b_{s}\right)$ & $0.96 \pm 0.16$ & $0.93 \pm 0.11$ \\
\hline Mean seed dispersal distance $\left(d_{s}\right)$ & $71 \mathrm{~m}[56-94]$ & $175 \mathrm{~m}$ [143-224] \\
\hline Seed dispersal anisotropy $\left(k_{s}\right)$ & $1.57 \pm 0.24$ & $0.0 \pm 0.16$ \\
\hline $\begin{array}{l}\text { Seed dispersal prevailing direction } \\
\left(a_{s}\right)\end{array}$ & $0.72 \pm 0.02(W)$ & / \\
\hline Effect of dbh on female fitness & $0.08 \pm 0.20$ & $0.32 \pm 0.10$ \\
\hline $\begin{array}{l}\text { Effect of crown dominance on } \\
\text { female fitness }\end{array}$ & $1.02 \pm 0.28$ & $0.02 \pm 0.11$ \\
\hline
\end{tabular}

TABLE 1 Pollen and seed dispersa parameters and selection gradients estimated by the neighbourhood model $(\mathrm{NM} \pi)$ applied on data sets 1 for each species, and indirect estimation of selfing rate of adults $\left(s_{a}\right)$ based on identity disequilibrium (estimate \pm standard error or estimate [95\% confidence interval]) 


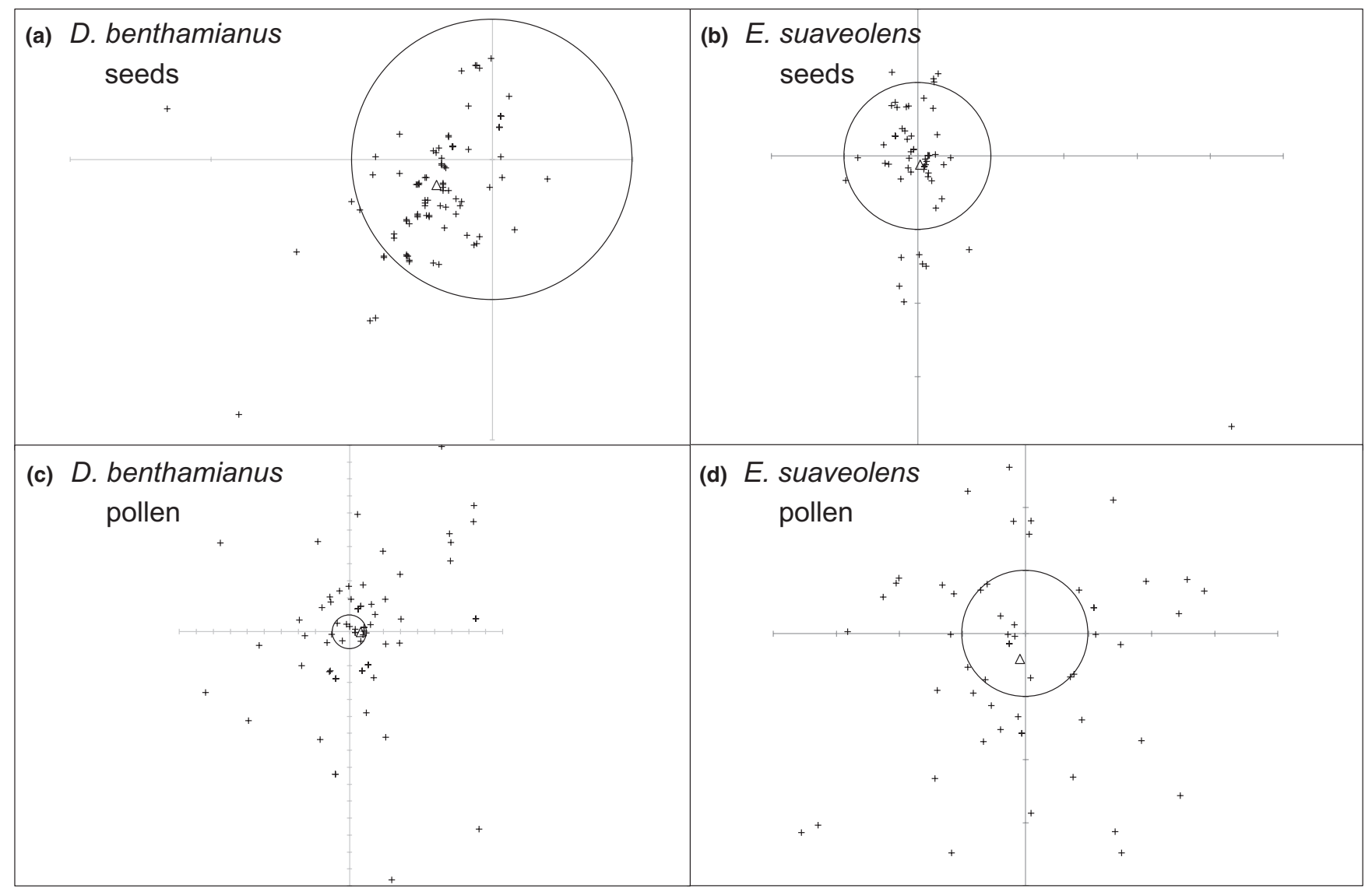

FIGURE 4 Two-dimensional dispersal distributions of seeds (above) and pollen (below) for Distemonanthus benthamianus (left, prelogging data set) and Erythrophleum suaveolens (right; North pointing upwards). Propagule dispersal events (+ symbols) inferred with $p>0.8$ are represented after centring the latitudinal and longitudinal displacements on the source $(0,0$ coordinates). The circles have a radius of $100 \mathrm{~m}$. The triangle symbols indicate the mean vector of dispersal events, the further it is from the origin, the more anisotropy occurs

D. benthamianus and $+4 \%$ in E. suaveolens) and seed migration rates (+0.6\% in D. benthamianus and $+0.8 \%$ in E. suaveolens) (Table S2). The estimates based on $D$. benthamianus seedlings sampled after logging (data set 3) were also similar, confirming dispersal anisotropy in the same direction (Table S2), the main differences being the absence of selfing, a lower rate of seed immigration $\left(m_{\mathrm{s}}=17 \% \pm 4 \%\right)$ and a more fat-tailed seed dispersal kernel $\left(b_{s}=0.24 \pm 0.17\right)$. The estimates after removing dispersed seeds of $E$. suaveolens (data set 3 ) showed lower seed dispersal distances $\left(d_{\mathrm{s}}=92 \mathrm{~m}, 95 \% \mathrm{Cl}\right.$ : 72-127 m) and a trend of higher seed immigration rate $\left(m_{s}=28 \% \pm 7 \%\right.$; Table $\left.S 2\right)$.

In D. benthamianus, among the 190 seedlings and 41 dispersed seeds, 46 (20\%) of them had a probability of being immigrant $\geq 80 \%$ according to $\mathrm{NM} \pi$. They were scattered across the sampling area (Figure S2a) and were not particularly close to a border (contrary to expectation if most immigrants came from mother trees located just outside the sampling area), or concentrated at a few locations (contrary to expectation if most seedlings came from a few missed mother trees). Hence, they must result from actual long-distance seed dispersal events. In E. suaveolens, among the 109 seedlings and 138 dispersed seeds, only $9(4 \%)$ of them had a probability of being immigrant $\geq 80 \%$ (Figure S2b).

\section{5 | Determinants of reproductive success- selection gradients}

In $D$. benthamianus, the male and female reproductive successes were uncorrelated with the $\mathrm{dbh}$ of trees (selection gradients: $g=0.08 \pm 0.20$ for female, $b=0.03 \pm 0.11$ for male functions) but well with the dominance status of the crown $(g=1.02 \pm 0.28$, $b=0.63 \pm 0.15)$, trends confirmed using the seedlings sampled after logging (data set 3 , Table S2). On the contrary, in E. suaveolens there was no significant impact of crown dominance $(g=0.02 \pm 0.11$, $b=-0.09 \pm 0.13$ ) but a weak impact of dbh ( $g=0.32 \pm 0.10$, $b=0.23 \pm 0.12$ ). These values were obtained by estimating simultaneously selection gradients of $\mathrm{dbh}$ and dominance, two correlated traits ( $r=0.49$ in D. benthamianus, $r=0.41$ in E. suaveolens). When selection gradients were estimated for each trait separately (fixing $b=g=0$ for the other trait), the effect of dbh became significant in $D$. benthamianus ( $g=0.50 \pm 0.14, b=0.24 \pm 0.09$ ), while the effect of crown dominance remained nonsignificant in $E$. suaveolens ( $g=0.17 \pm 0.10, b=0.02 \pm 0.11$ ). The comparison of the distributions of $\mathrm{dbh}$ and dominance status for all trees, trees identified as mother and trees identified as father illustrates these trends (Figure 5). 


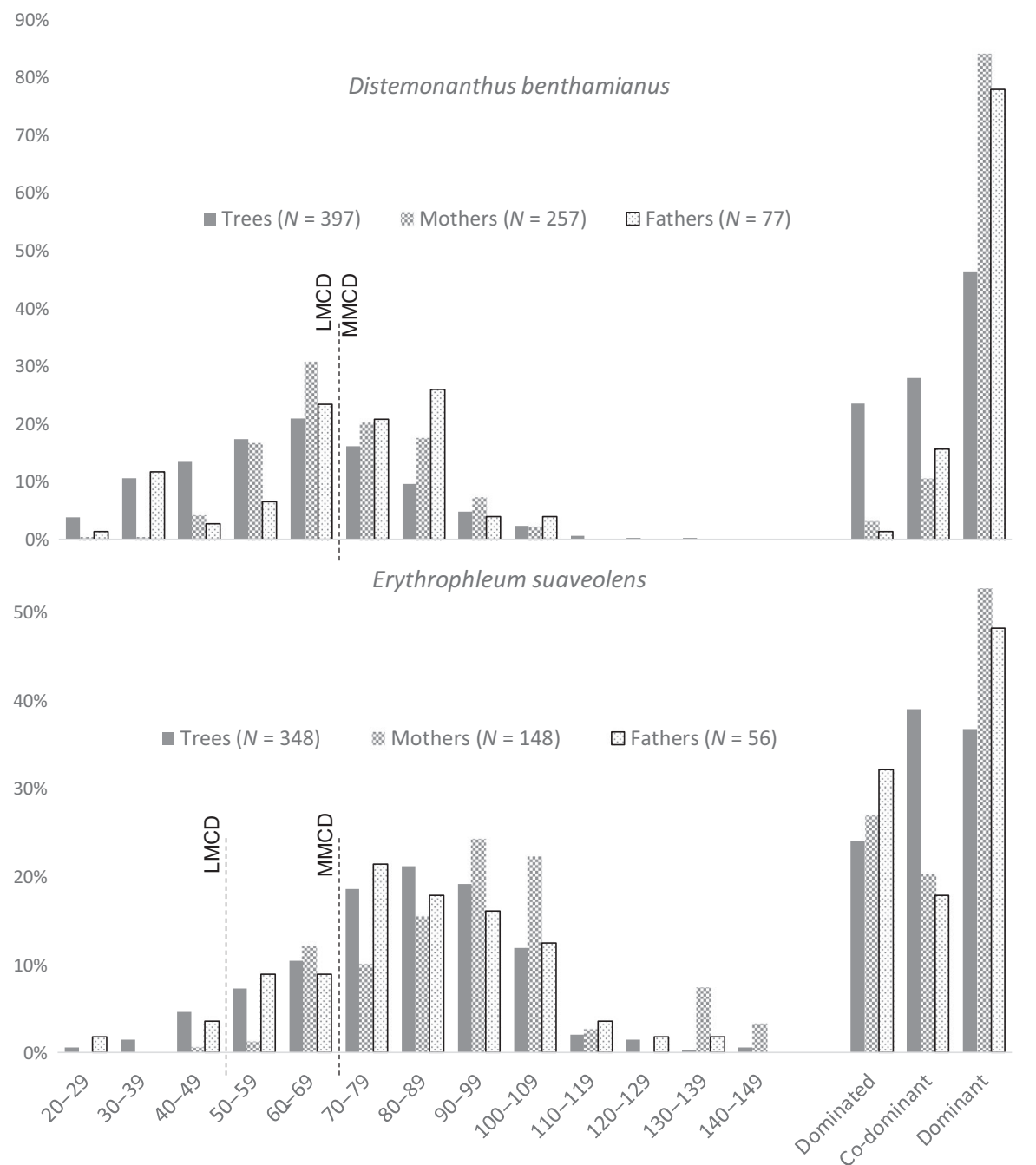

FIGURE 5 Distributions of diameter classes and of degree of canopy dominance of sampled trees and of trees identified as mother or father, for Distemonanthus benthamianus (above) and Erythrophleum suaveolens (below). The stippled line indicates the legal (LMCD) and/or management (MMCD) minimum cutting diameters

\section{6 | Predicted migration rates and backward dispersal distances from forward dispersal kernels}

In $D$. benthamianus, the simulations using the best fitting seed and pollen dispersal kernels and assuming that $95 \%$ of the adults had been sampled, indicated that pollen and seed migration rates should reach c. $20.5 \%$ (range $19.6 \%-21.5 \%$ over 20 replicates) and $4.5 \%$ (range $0.9 \%-12.7 \%$ ), respectively, values much lower than the $m_{p}=52 \%$ and $m_{s}=30 \%$ estimated by NM $\pi$. As the pollen dispersal kernel was fat-tailed $\left(b_{p}=0.40 \pm 0.12\right)$, we estimated again the kernel parameters using $\mathrm{NM} \pi$ when fixing $b_{\mathrm{p}}=0.20$ to consider an even more fat-tailed kernel that was still compatible with the data (allowing a decrease in the Log-likelihood of the data $<2$ units), in which case $d_{p}=2,170 \mathrm{~m}$. In these conditions, the simulations predicted $m_{p}=37.5 \%$ (range $36.1 \%-38.5 \%$ ), which approaches the estimated value $(52 \%)$ but remains lower. By contrast, in E. suaveolens the predicted pollen and seed migration rates using the best fitting kernels and assuming that $87 \%$ of the adults had been sampled within the sampling area, reached $23 \%$ and $15 \%$, congruent with the estimated rates $m_{p}=22 \%$ and $m_{s}=18 \%$.

Our simulations gave backward dispersal distances of $75 \mathrm{~m}$ for seeds and $706 \mathrm{~m}$ for pollen in $D$. benthamianus, and $160 \mathrm{~m}$ for seeds and $278 \mathrm{~m}$ for pollen in E. suaveolens, values very close to the mean forward dispersal distances (Table 1). The mean distances of seed and pollen dispersal events detected at $p>0.8$ (Figure 4) were however smaller, being 61 and $384 \mathrm{~m}$ in D. benthamianus, 95 and $183 \mathrm{~m}$ in E. suaveolens. This illustrates that describing dispersal kernels from the distribution of dispersal distances of detected events substantially underestimates the actual kernels due to the limited size of the sampling area in comparison with actual dispersal distances.

\section{7 | Spatial genetic structure and assortative mating}

The kinship-distance curves showed a regular decay, near linear with $\log$ (distance) (Figure 6). The two species displayed very similar fine-scale spatial genetic structures, except at $<100 \mathrm{~m}$ where $D$. benthamianus adults were twice more related than $E$. suaveolens adults (mean $F_{i j}$ between adults separated by $<50 \mathrm{~m}$, respectively, equal to 0.064 and 0.033 , Figure 6).

In $D$. benthamianus, 68 mating pairs were detected with a probability $\geq 0.8$, after excluding selfing events. The mean pairwise kinship coefficient between these mates reached 0.011 when computed from their genotypes, which is not significantly different from 0.015 , 


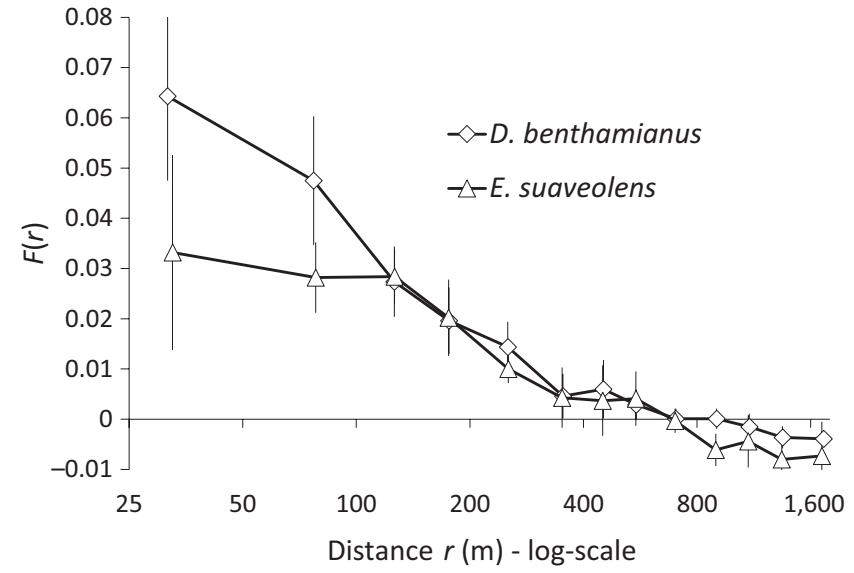

FIGURE 6 Fine-scale spatial genetic structures of Distemonanthus benthamianus (diamonds) and Erythrophleum suaveolens (triangles) assessed by the kinship-distance decay. Higher kinship at distances $<100 \mathrm{~m}$ in $D$. benthamianus is interpreted as reflecting the impact of short seed dispersal in this species, causing a higher proportion of mother-offspring and openpollinated sib pairs among neighbouring trees than in E. suaveolens

the mean expected value based on the kinship-distance curve and the spatial distance separating the mates ( $p_{\text {val }}$ of $t$ test for paired samples $=0.65$ ). By contrast, in $E$. suaveolens, the mean pairwise kinship coefficient between 63 mating pairs detected at a probability $\geq 0.8$ reached 0.065 , which is significantly larger than 0.019 , the mean expected value accounting for limited pollen dispersal (Pval of $t$ test for paired samples $=0.019$ ). Hence, there is evidence of assortative mating occurring in E. suaveolens but not in D. benthamianus.

\section{4 | DISCUSSION}

Seed and pollen dispersal patterns in the two studied species differ strikingly, despite the facts that these species belong to the same family, have similar light requirements (long-lived, light-demanding trees) and were studied in populations with comparable densities (111 vs. $178 \mathrm{ind} / \mathrm{km}^{2}$ ). First, pollen dispersal appears much more extensive in Distemonanthus benthamianus than in Erythrophleum suaveolens which shows higher selfing rate. Second, most seeds disperse less in D. benthamianus than in E. suaveolens. Nevertheless, seed and pollen immigration rates, indicating long-distance dispersal, were much higher in $D$. benthamianus than in E. suaveolens. Our simulations furthermore showed that the observed immigration rates could be explained by the modelled dispersal kernels in E. suaveolens but not in $D$. benthamianus, where long-distance dispersal is therefore more frequent than described by the fitted kernels. The two species also differed in terms of (a) dispersal anisotropy, detected for $D$. benthamianus seeds and possibly E. suaveolens pollen, and (b) by the factors explaining their reproductive success (canopy dominance for $D$. benthamianus and dbh for E. suaveolens). Signs of inbreeding depression and of assortative mating were found in $E$. suaveolens but not in $D$. benthamianus. Hereafter, we discuss the possible origins of these differences, in particular in relation to pollen and seed dispersal vectors, and their consequences for sustainable logging.

\section{1 | Pollen dispersal, mating system and inbreeding}

One factor affecting the effective pollen dispersal distances is the population density, as shown in E. suaveolens where indirect estimates increased from c. 200 to $1,000 \mathrm{~m}$ when the density of adults dropped from 175 to 11 adults $/ \mathrm{km}^{2}$ (Duminil et al., 2016). The adult density is lower in the $D$. benthamianus population (114 adults $/ \mathrm{km}^{2}$ ) than the E. suaveolens one (175 adults $/ \mathrm{km}^{2}$ ) but certainly not lower enough to explain the much larger pollen dispersal distances observed (mean distance c. 700 vs. 300 m; Table 1). The contrast in pollen dispersal distances is even higher because in $D$. benthamianus the modelled kernel failed to explain the large amount of pollen immigration (c. 50\%), while potential fathers were nearly exhaustively sampled in a radius of $1 \mathrm{~km}$ around most maternal trees. Hence, most of the pollen disperses $>1 \mathrm{~km}$ away in this species. The shape of the modelled pollen dispersal kernel is also much more fat-tailed in $D$. benthamianus $\left(b_{p}=0.4\right)$ than in E. suaveolens where it fits an exponential distribution ( $b_{\mathrm{p}}$ not significantly different from 1$)$. The low $b_{\mathrm{p}}$ value in $D$. benthamianus explains the low accuracy of the estimated mean pollen dispersal distance (Table 1) because small variation in $b_{\mathrm{p}}$ estimates translates in large variation in $d_{\mathrm{p}}$ estimates when $b_{p}<1$. The low dispersal shape $b_{p}$ is explained by the fact that still a non-negligible part of the pollen disperses over relatively short distances. In E. suaveolens, the low pollen immigration rate (22\%), which can be explained by border effects and the limited exhaustiveness of the adult sampling, combined with the exponential pollen dispersal kernel (i.e., without fat tail) indicate that long-distance pollen dispersal events must be rare in the studied population. This may a priori cause problems of pollen limitation in low-density populations. Nevertheless, Duminil et al. (2016) reported indirect estimates of E. suaveolens pollen dispersal distances of c. $1,000 \mathrm{~m}$ in a low-density population, without increase in selfing rate. Hence, either E. suaveolens pollinators might still have the ability to fly long distances when they need because floral resources are more sparsely distributed, or wind could contribute significantly to pollen dispersal.

Differences in pollen dispersal vectors probably explain the contrasted pollen dispersal kernels observed between the two species. Knowledge on pollination biology of canopy trees is still very fragmentary, partly because observing the flowering in the canopy is challenging. We can therefore rely only on the relationship between floral morphology and pollination syndromes. The two species present very different hermaphrodite flowers: the large zygomorphic $D$. benthamianus flowers display three white petals and two large stamens (up to $1.5 \mathrm{~cm}$ ) terminated by dark anthers, creating a particular shape (Figure 2) that may attract pollinators with a fairly large body size. The small actinomorphic E. suaveolens flowers, c. $5 \mathrm{~mm}$ long, have highly reduced sepals and petals, leaving stamens directly exposed. The spike-like inflorescences thus display densely packed flowers with easily accessible pollen (Figure 2). This floral structure seems to correspond to a generalist pollination syndrome that could 
attract many insect species, consistent with observations on the Asian congeneric species $E$. fordii which bears similar inflorescences and is visited by beetles (Cerambycidae), butterflies (Papilionidae), bees and wasps (Zhu, Ye, Cao, Wang, \& Saravanan, 2013). If D. benthamianus is pollinated by large specialized pollinators able to perform long-distance flights and $E$. suaveolens is pollinated by less mobile generalist pollinators, this could explain why these species differ so much in pollen dispersal patterns. Identifying the pollinators of these species, and of other tropical tree species, is obviously important to better understand what determine pollen dispersal capacities in tropical forests. A relationship between flower size, pollinator size and pollen dispersal distance has been reported in two Dipterocarp rainforest canopy tree species (Kettle et al., 2011). It should be noted that small pollinators are not necessarily short distance flyers, as fig-wasps are very efficient long-distance specialized pollinators (Ahmed, Compton, Butlin, \& Gilmartin, 2009), but the relationship between body size and dispersal distances is probably more valid for generalist pollinators who should avoid losing energy in seeking floral resources. Whether wind pollination could also occur in E. suaveolens is unknown but not supported by trials made on E. fordii (Zhu et al., 2013). Nevertheless, it would also explain the trend of pollen dispersal anisotropy.

Erythrophleum suaveolens showed more selfing (20\%) than D. benthamianus (6\%), which could be explained by an increase in geitonogamy due to more limited dispersal distances in E. suaveolens. However, the absence of impact of population density on selfing rate (Duminil et al., 2016) is not supporting this hypothesis. Selfing rate could also be controlled by partial self-incompatibility systems, which may differ between species. Assortative mating, which has recently been detected in another African tree species (Monthe et al., 2017), has been found in E. suaveolens but not in $D$. benthamianus. This phenomenon might arise when the variation in flowering phenology between individuals is under genetic control, in which case more related individuals would have more overlapping flowering periods. We lack flowering phenological data to confirm this possible mechanism, but it shows that E. suaveolens is prone to inbreeding both due to selfing and assortative mating. It is also the sole species showing signs of inbreeding depression by the lower inbreeding found in adults compared with juveniles, although a strict demonstration of inbreeding depression would require direct observations of fitness components between selfed and outcrossed individuals. As a result, while the proportion of selfed and/or inbred individuals is much higher in E. suaveolens than in $D$. benthamianus at the seed and seedling stages, the pattern reverses at the adult stage.

\section{2 | Seed dispersal}

Mean forward seed dispersal distances were larger in E. suaveolens (c. $175 \mathrm{~m}$ ) than in D. benthamianus (c. $70 \mathrm{~m}$ ), and much more seeds collected below trees were secondarily dispersed in $E$. suaveolens $(\geq 45 \%$ ) than in $D$. benthamianus (11\%). Seed dispersal distances appeared less extensive in E. suaveolens (c. $92 \mathrm{~m}$ ) when only seedlings were considered (i.e., excluding dispersed seeds sampled below trees). Distemonanthus benthamianus produces indehiscent papery pods better dispersed by wind than the typical dehiscent $E$. suaveolens pods. Longer seed dispersal in E. suaveolens therefore results from secondary zoochorous dispersal, consistently with the observation that different animals like the mucilage surrounding fresh seeds (Guion, 2011). This fauna includes long-distance dispersers like gorillas, for which the hard coated seeds remain intact after the gut passage (Petre et al., 2015). It seems however that most seeds were not dispersed by such large primates because we would have then expected dispersal over a few kilometres (Petre et al., 2013), hence a higher rate of seed immigration. Maybe primates like to suck E. suaveolens seeds and spit them out later, possibly below another tree, explaining longer distance dispersal for dispersed seeds found below trees. Ground rodents may also play a significant role and the scale of dispersal observed seems consistent with their typical dispersal capacity (Evrard, Haurez, \& Doucet, 2017).

In both species, the modelled seed dispersal kernels are close to exponential distributions, although fat-tailed dispersal was detected for seedlings sampled after logging in D. benthamianus. In E. suaveolens, the fairly low seed immigration rate (17\%) could be explained by a border effect and missed adults within the sampling area, so that long-distance seed dispersal seems rare. By contrast, while most $D$. benthamianus seeds disperse over short distances, we detected $30 \%$ of seed immigration, a rate that could not be explained by missing adults or border effects according to our simulations. Hence, seed dispersal is in fact extremely fat-tailed in $D$. benthamianus, the fitted dispersal kernel having modelled only the small-distance dispersal events within the sampling plot. Wind dispersal might explain this peculiar pattern if we assume that long-distance dispersal occurs when very strong winds or storms bring pods above the canopy layer in turbulent flows. The peduncle of pods may in fact break mostly under such circumstances, favouring efficient dispersal even though these pods are not really good flyers. Pods not taken in such turbulent flow would fly down directly from the canopy layer and disperse $<100 \mathrm{~m}$ in most cases, a scale consistent with wind-dispersed Dipterocarp trees (Smith et al., 2016). Distemonanthus benthamianus seed dispersal showed strong anisotropy, consistent across all data sets, as could be expected under wind dispersal.

\subsection{Forward dispersal kernels versus backward migration rates}

The R script developed to check whether the dispersal kernels estimated by $N M \pi$ correctly predicted immigration rates showed that this was not the case in $D$. benthamianus for both seed and pollen, long-distance dispersal remaining underestimated by the kernels, despite the extensive sampling area $\left(c .6 \mathrm{~km}^{2}\right)$. Our approach is thus useful to complement NM $\pi$ analyses and assess long-distance dispersal. In principle, dispersal kernels could be fitted to account for immigration rates if the distribution of trees outside the sampling 
area was known approximately. However, many different kernel families might fit equally well the data so that the shape of the kernel at distances larger than the size of the sampling area would probably remain difficult to assess reliably.

\section{4 | Implications for natural regeneration after selective logging}

Unexpectedly, D. benthamianus seed dispersal estimated from seedlings sampled 6 years after logging (data set 3 ) led to lower seed immigration rate ( $17 \%$ instead of $30 \%)$. A reverse pattern would a priori be expected if logging had reduced substantially local seed production. However, few D. benthamianus were exploited (c. 4\%), and as light availability appears determinant for the reproductive success of this species (high impact of dominance status), logging might have increased the local seed production for $D$. benthamianus trees through the logging of other species, resulting in lower immigration rate. This highlights the necessity to study how logging affects seed production and seedling establishment to predict its actual impact on regeneration.

In Cameroon, the LMCD of E. suaveolens is $50 \mathrm{~cm}$ (Fayolle et al., 2013), and in Gabon, the LMCD of $D$. benthamianus is $70 \mathrm{~cm}$ (Meunier, Moumbogou, \& Doucet, 2015). In our D. benthamianus plot, set up in CEB logging concession where the MMCD equals the LMCD, 34\% of trees were above the LMCD and this percentage rose to $47 \%$ and $55 \%$ in terms of female and male reproductive potential, respectively (Figure 5). Hence, even if all trees above the LMCD were exploited, still about half of the reproductive potential would remain. At the scale of the whole UFA, data from the management inventories (CEB, pers. comm.) indicate that only $11 \%$ of trees were above the LMCD, further limiting the impact of logging on the reproductive potential. The distance between nearest dominant trees would increase from $65 \pm 39$ m (mean $\pm S D$ ) to $94 \pm 53 \mathrm{~m}$ if all commercial trees ( $\mathrm{dbh} \geq 70 \mathrm{~cm}$, LMCD) were logged, distances low compared with the inferred pollen dispersal distances, so that cross-pollination is not expected to be a limiting factor. Seeds being dispersed by wind and over long distances for $15 \%$ to $30 \%$ of them, a decrease in adult density should not affect significantly the seed rains in microhabitats suitable for seedling establishment. Therefore, given that the opening of the forest after logging favours light-demanding species such as $D$. benthamianus, whose seeds are dormant and seedlings mostly found in canopy gaps and along an ancient forestry road, we infer that an exploitation respecting the LMCD in Gabon should maintain sufficient regeneration potential for this species.

In the E. suaveolens FMU, set up in Pallisco logging concessions, the MMCD is $70 \mathrm{~cm}, 20 \mathrm{~cm}$ above the LMCD. In the study plot, $93 \%$ of trees were above the LMCD and $75 \%$ above the MMCD, percentages that remained identical in terms of male reproductive potential but that increased to $99 \%$ above the LMCD and $86 \%$ above the MMCD in terms of female reproductive potential (Figure 5). Hence, if all trees above the LMCD were exploited, the regeneration capacity of the species would decrease dramatically, and it would still be strongly reduced if all trees above the MMCD were exploited. At the scale of the FMU, management inventories indicate that $74 \%$ of trees are above the LMCD and $42 \%$ above the MMCD, so that the impact of exploitation would be less severe. Moreover, the impact on the regeneration potential would also be tempered somewhat by dormant seeds of this light-demanding species that could germinate in openings resulting from tree harvesting (Kleinschroth, Healey, Sist, Mortier, \& Gourlet-Fleury, 2016). The distance between nearest trees in the plot was $39 \pm 23 \mathrm{~m}$ and would increase to $82 \pm 47 \mathrm{~m}$ if all trees above the MMCD were removed, distances still much lower than the mean pollen dispersal distance (c. 300 m). Thus, cross-pollination is not expected to become a limiting factor under such exploitation regime, a result consistent with the absence of impact of population density on selfing (Duminil et al., 2016). Long-distance seed dispersal depends much on mammals which could suffer from increased hunting. Such an impact is not expected in the studied concession where antipoaching measures are applied and efficient. In nonmanaged logging concessions, less efficient seed dispersal could limit seed rains in favourable sites and eventually increase inbreeding in this species which suffers from inbreeding depression. Nowadays, the species has often a bell-shaped population structure in all its range since it regenerated by the end of the 19th century in abandoned fields (Morin-Rivat et al., 2017). In Central Africa, the LMCD was fixed by national regulations for commercial reasons without any ecological consideration. Hence, the LMCD of E. suaveolens varies from $50 \mathrm{~cm}$ (Cameroon) to $80 \mathrm{~cm}$ (Central African Republic; Ouédraogo et al., 2018). Ouédraogo et al. (2018) found that the probability of fructification, while it was site-dependent, was lower than $50 \%$ at $60 \mathrm{~cm}$. Our results confirm that the LMCD of $50 \mathrm{~cm}$ in Cameroon is probably too low to secure a sufficient number of seed trees.

\section{5 | Recommendations for sustainable management}

Our results indicate that natural regeneration in the two studied populations should not be limited by seed and pollen dispersal capacities (Figure 1), despite the contrasted differences observed between the two species. However, for E. suaveolens, trees with a dbh below the LMCD contribute little to the reproduction, highlighting the need to characterize the relationship between $\mathrm{dbh}$ and reproductive success to develop sustainable management practices (Figure 4).

Three possibilities can be proposed in order to limit the impact of logging on E. suaveolens: (a) the LMCD should be harmonized through producing countries and fixed at $70 \mathrm{~cm}$, (b) a minimal percentage of trees above MMCD should be left unlogged to avoid a drastic reduction in the regeneration potential (in order to maintain about half of the initial female reproductive potential) and (c) the reduction in seed trees should be offset by planting nursery-raised seedlings in logging gaps. The later action is applied in the FSC-certified forest concessions studied (Doucet, Kouadio, Monticelli, \& Lejeune, 2009). For species prone to inbreeding depression, such as E. suaveolens, planting siblings close to each other must be avoided. 
More generally, managers must ensure that seeds used in such nurseries come from a diverse array of seed trees.

In conclusion, management strategies locally adopted have an important influence on the regeneration potential of timber species and models need to be developed to investigate the impact of multiple cutting cycles. To which extent the canopy openings following logging activities favour the natural regeneration of light-demanding species, especially those with dormant seeds, remains to be investigated to better model the regeneration potential.

\section{ACKNOWLEDGEMENTS}

We thank Pallisco, CEB-Precious Wood and Nature+, for providing logistic support for the fieldwork. We are especially grateful to Paul Lagoute, Philippe Jeanmart, Théophile Ayol Missuh, Armel Donkpegan, Augustin Assam, Crépin Ndjopandé, Gabriel Nguele, Armand Boudady and Kasso Daïnou. We thank three anonymous reviewers and Victoria Sork for their constructive comments on a previous draft. This work was funded by the F.R.S.-FNRS (grant no. X.3040.17, project AFRITIMB), the Belgian Science Policy (Belspo, project AFRIFORD) and the Fonds Français pour l'Environnement Mondial (projects Dynaffor $\mathrm{N}^{\circ} \mathrm{CZZ1636.01D}, \mathrm{N}^{\circ} \mathrm{CZZ1636.02D}$ and P3FAC $\mathrm{N}^{\circ} \mathrm{CZZ201.01R).}$

\section{AUTHOR CONTRIBUTIONS}

O.J.H., J.D. and J.L.D. conceived the research. O.J.H., B.D., J.F.G., P.G. and H.H. performed the field work with local workers. B.D., P.G., H.H., E.K., N.V. and J.D. performed the genotyping. O.J.H., B.D., P.G., H.H., N.V. and J.D. conducted data analyses. O.J.H., J.L.D. and J.D. wrote the manuscript. All authors commented and approved the manuscript.

\section{DATA ACCESSIBILITY}

Sampling locations, morphological data, mother of seeds and microsatellite genotypes (all in NM $\pi$ input file format for data sets 1 to 3 for each species): Dryad DOI: https://doi.org/10.5061/dryad.668fk8r.

$\mathrm{R}$ code to estimate immigration rates and backward dispersal kernels from forward dispersal kernels using input and output NM $\pi$ files, as well as examples of input and output $N M \pi$ files, are provided as Appendix S1, S2 and S3.

\section{REFERENCES}

Abernethy, K. A., Coad, L., Taylor, G., Lee, M. E., \& Maisels, F. (2013). Extent and ecological consequences of hunting in Central African rainforests in the twenty-first century. Philosophical Transactions of the Royal Society B: Biological Sciences, 368(1625), 20120303. https:// doi.org/10.1098/rstb.2012.0303

Ahmed, S., Compton, S. G., Butlin, R. K., \& Gilmartin, P. M. (2009). Windborne insects mediate directional pollen transfer between desert fig trees 160 kilometers apart. Proceedings of the National Academy of Sciences of the United States of America, 106(48), 20342-20347. https ://doi.org/10.1073/pnas.0902213106

Ashley, M. V. (2010). Plant parentage, pollination, and dispersal: How DNA microsatellites have altered the landscape. Critical Reviews in Plant Sciences, 29(3), 148-161. https://doi.org/10.1080/07352 689.2010.481167

Aubréville, A. (1968). Légumineuses - Caesalpinioidées (Leguminosae - Caesalpinioideae). Flore du Gabon (vol. 15, 362 pp). Paris, France: Muséum National d'Histoire Naturelle.

Burczyk, J., Adams, W. T., Birkes, D. S., \& Chybicki, I. J. (2006). Using genetic markers to directly estimate gene flow and reproductive success parameters in plants on the basis of naturally regenerated seedlings. Genetics, 173(1), 363-372. https://doi.org/10.1534/genet ics.105.046805

Cavers, S., \& Cottrell, J. E. (2015). The basis of resilience in forest tree species and its use in adaptive forest management in Britain. Forestry, 88(1), 13-26. https://doi.org/10.1093/forestry/cpu027

Chybicki, I. J. (2018). NM $\pi$-improved re-implementation of $\mathrm{NM}+$, a software for estimating gene dispersal and mating patterns. Molecular Ecology Resources, 18(1), 159-168. https://doi. org/10.1111/1755-0998.12710

Chybicki, I. J., \& Burczyk, J. (2009). Simultaneous estimation of null alleles and inbreeding coefficients. Journal of Heredity, 100(1), 106113. https://doi.org/10.1093/jhered/esn088

Chybicki, I. J., \& Oleksa, A. (2018). Seed and pollen gene dispersal in Taxus baccata, a dioecious conifer in the face of strong population fragmentation. Annals of Botany, 122(3), 409-421. https://doi.org/10.1093/ aob/mcy081

Clark, J. S., Lewis, M., \& Horvath, L. (2001). Invasion by extremes: Population spread with variation in dispersal and reproduction. American Naturalist, 157(5), 537-554. https://doi. org/10.1086/319934

David, P., Pujol, B., Viard, F., Castella, V., \& Goudet, J. (2007). Reliable selfing rate estimates from imperfect population genetic data. Molecular Ecology, 16(12), 2474-2487. https://doi. org/10.1111/j.1365-294X.2007.03330.x

Debout, G. D. G., Doucet, J.-L., \& Hardy, O. J. (2011). Population history and gene dispersal inferred from spatial genetic structure of a Central African timber tree, Distemonanthus benthamianus (Caesalpinioideae). Heredity, 106(1), 88-99. https://doi.org/10.1038/ hdy.2010.35

Demenou, B. B., Piñeiro, R., \& Hardy, O. J. (2016). Origin and history of the Dahomey Gap separating West and Central African rain forests: Insights from the phylogeography of the legume tree Distemonanthus benthamianus. Journal of Biogeography, 43(5), 1020-1031. https://doi. org $/ 10.1111 /$ jbi.12688

Dick, C. W., Hardy, O. J., Jones, F. A., \& Petit, R. J. (2008). Spatial scales of pollen and seed-mediated gene flow in tropical rain forest trees. Tropical Plant Biology, 1(1), 20-33. https://doi.org/10.1007/ s12042-007-9006-6

Doucet, J.-L. (2003). L'alliance délicate de la gestion forestière et de la biodiversité dans les forêts du centre du Gabon. Gembloux, Belgium: Fac. Univ. Sci. Agron.

Doucet, J.-L., Daïnou, K., Ligot, G., Ouédraogo, D.-Y., Bourland, N., Ward, S. E., ... Fayolle, A. (2016). Enrichment of Central African logged forests with high-value tree species: Testing a new approach to regenerating degraded forests. International Journal of Biodiversity Science, Ecosystem Services and Management, 12(1-2), 83-95. https://doi. org/10.1080/21513732.2016.1168868

Doucet, J.-L., Kouadio, Y. L., Monticelli, D., \& Lejeune, P. (2009). Enrichment of logging gaps with moabi (Baillonella toxisperma Pierre) in a Central African rain forest. Forest Ecology and Management, 258(11), 2407-2415. https://doi.org/10.1016/j. foreco.2009.08.018

Duminil, J., Daïnou, K., Kaviriri, D. K., Gillet, P., Loo, J., Doucet, J.-L., \& Hardy, O. J. (2016). Relationships between population density, finescale genetic structure, mating system and pollen dispersal in a timber tree from African rainforests. Heredity, 116(3), 295-303. https:// doi.org/10.1038/hdy.2015.101 
Duminil, J., Koffi, G. K., Debout, G., Sebastiani, F., Vendramin, G. G., Heuertz, M., ... Hardy, O. J. (2011). Isolation of SSR markers for two African tropical tree species, Erythrophleum suaveolens and E. ivorense (Caesalpinioideae). American Journal of Botany, 98(5), e106-e108. https://doi.org/10.3732/ajb.1000482

Duminil, J., Mendene, A., Ndiade, B., Doucet, J.-L., Loo, J., \& Hardy, O. J. (2016). High selfing rate, limited pollen dispersal and inbreeding depression in the emblematic African rain forest tree Baillonella toxisperma - Management implications. Forest Ecology and Management, 379, 20 29. https://doi.org/10.1016/j.foreco.2016.08.003

Evrard, Q., Haurez, B., \& Doucet, J.-L. (2017). The role of rodents in the regeneration of forest ecosystems. A review. Biotechnology, Agronomy and Society and Environment, 21(1), 66-79.

Fayolle, A., Rondeux, J., Doucet, J.-L., Ernst, G., Bouissou, C. Quevauvillers, S., ... Lejeune, P. (2013). Revising volume tables for better management of Cameroon's forests. Bois et Forêts des Tropiques, 67(317), 35-49.

Finger, A., Kettle, C. J., Kaiser-Bunbury, C. N., Valentin, T., Mougal, J., \& Ghazoul, J. (2012). Forest fragmentation genetics in a formerly widespread island endemic tree: Vateriopsis seychellarum (Dipterocarpaceae). Molecular Ecology, 21(10), 2369-2382. https:// doi.org/10.1111/j.1365-294X.2012.05543.x

García, C., Klein, E., Jordano, P., \& Rees, M. (2016). Dispersal processes driving plant movement: Challenges for understanding and predicting range shifts in a changing world. Journal of Ecology, 105(1), 1-5. https://doi.org/10.1111/1365-2745.12705

Gautier-Hion, A., Gautier, J. P., \& Maisels, F. (1993). Seed dispersal versus seed predation: An inter-site comparison of two related African monkeys. Plant Ecology, 107(108), 237-244.

Guion, H. (2011). Etude de l'écologie d'Erythrophleum suaveolens (Guill. \& Perr.) Brenan (tali) et de l'origine de ses peuplements au sud-est du Cameroun. (Master thesis). GxABT-University of Liège, Belgium.

Hampe, A., Masri, L. E., \& Petit, R. J. (2010). Origin of spatial genetic structure in an expanding oak population. Molecular Ecology, 19(3), 459-471. https://doi.org/10.1111/j.1365-294X.2009.04492.x

Hardy, O. J., \& Vekemans, X. (2002). SPAGeDi: A versatile computer program to analyse spatial genetic structure at the individual or population levels. Molecular Ecology Notes, 2(4), 618-620. https://doi. org/10.1046/j.1471-8286.2002.00305.x

Haurez, B., Petre, C.-A., \& Doucet, J.-L. (2013). Impacts of logging and hunting on western lowland gorilla (Gorilla gorilla gorilla) populations and consequences for forest regeneration. A review. Biotechnology, Agronomy and Society and Environment, 17(2), 364-372.

Hecketsweiler, P. (1992). Phénologie et saisonnalité en forêt gabonaise, l'exemple de quelques espèces ligneuses. PhD thesis, Université de Montpellier II, 266 pp.

Ismail, S. A., Ghazoul, J., Ravikanth, G., Kushalappa, C. G., Uma, S., \& Kettle, C. J. (2017). Evaluating realized seed dispersal across fragmented tropical landscapes: a two-fold approach using parentage analysis and the neighbourhood model. New Phytologist, 214(3), 1307-1316. https://doi.org/10.1111/nph.14427

Kalinowski, S. T., Taper, M. L., \& Marshall, T. C. (2007). Revising how the computer program CERVUS accommodates genotyping error increases success in paternity assignment. Molecular Ecology, 16(5), 1099-1106. https://doi.org/10.1111/j.1365-294X.2007.03089.x

Kettle, C. J., Maycock, C. R., Ghazoul, J., Hollingsworth, P. M., Khoo, E., Sukri, R. S. H., \& Burslem, D. F. R. P. (2011). Ecological implications of a flower size/number trade-off in tropical forest trees. PLOS ONE, 6(2), e16111. https://doi.org/10.1371/journal.pone.0016111

Klein, E. K., Desassis, N., \& Oddou-Muratorio, S. (2008). Pollen flow in the wildservice tree, Sorbus torminalis (L.) Crantz. IV. Whole interindividual variance of male fecundity estimated jointly with the dispersal kernel. Molecular Ecology, 17(14), 3323-3336. https://doi. org/10.1111/j.1365-294X.2008.03809.x
Kleinschroth, F., Healey, J. R., Sist, P., Mortier, F., \& Gourlet-Fleury, S. (2016). How persistent are the impacts of logging roads on Central African forest vegetation? Journal of Applied Ecology, 53(4), 1127-1137.

Kouadio, Y. L. (2009). Mesures sylvicoles en vue d'améliorer la gestion des populations d'essences forestières commerciales de l'Est du Cameroun(PhD Thesis). Fac. Univ. Sci. Agron., Gembloux, Belgium.

Lander, T. A., Bebber, D. P., Choy, C. T. L., Harris, S. A., \& Boshier, D. H. (2011). The Circe principle explains how resource-rich land can waylay pollinators in fragmented landscapes. Current Biology, 21(15), 1302-1307. https://doi.org/10.1016/j.cub.2011.06.045

Lefèvre, F., Boivin, T., Bontemps, A., Courbet, F., Davi, H., DurandGillmann, M., ... Pichot, C. (2014). Considering evolutionary processes in adaptive forestry. Annals of Forest Science, 71(7), 723-739. https://doi.org/10.1007/s13595-013-0272-1

Loiselle, B. A., Sork, V. L., Nason, J., \& Graham, C. (1995). Spatial genetic structure of a tropical understory shrub, Psychotria officinalis (Rubiaceae). American Journal of Botany, 82(11), 1420-1425.

LPWG (2017). A new subfamily classification of the leguminosae based on a taxonomically comprehensive phylogeny. The Legume Phylogeny Working Group (LPWG). Taxon, 66(1), 44-77. https://doi. org/10.12705/661.3

Marshall, T. C., Slate, J., Kruuk, L. E. B., \& Pemberton, J. M. (1998). Statistical confidence for likelihood-based paternity inference in natural populations. Molecular Ecology, 7(5), 639-655. https://doi. org/10.1046/j.1365-294x.1998.00374.x

Maurer, K. D., Bohrer, G., Medvigy, D., Wright, S. J., \& Thompson, K. (2013). The timing of abscission affects dispersal distance in a winddispersed tropical tree. Functional Ecology, 27, 208-218. https://doi. org/10.1111/1365-2435.12028

Meunier, Q., Moumbogou, C., \& Doucet, J.-L. (2015). Les arbres utiles du Gabon. Retrieved from https://orbi.uliege.be/handle/2268/183815

Monthe, F. K., Hardy, O. J., Doucet, J.-L., Loo, J., \& Duminil, J. (2017). Extensive seed and pollen dispersal and assortative mating in the rain forest tree Entandrophragma cylindricum (Meliaceae) inferred from indirect and direct analyses. Molecular Ecology, 26(19), 52795291. https://doi.org/10.1111/mec.14241

Morin-Rivat, J., Fayolle, A., Favier, C., Bremond, L., Gourlet-Fleury, S., Bayol, N., ... Doucet, J.-L. (2017). Present-day central African forest is a legacy of the 19th century human history. ELife, 6, e20343. https:// doi.org/10.7554/elife. 20343

Nathan, R. (2008). Long-distance dispersal of plants (Science (2006) (786)). Science, 322(5900), 375. https://doi.org/10.1126/scien ce.322.5900.375

Nathan, R., Katul, G., Bohrer, G., Kuparinen, A., Soons, M., Thompson, S., ... Horn, H. (2011). Mechanistic models of seed dispersal by wind. Theoretical Ecology, 4, 113-132.

Ouédraogo, D.-Y., Doucet, J.-L., Daïnou, K., Baya, F., Biwolé, A. B., Bourland, N., ... Fayolle, A. (2018). The size at reproduction of canopy tree species in central Africa. Biotropica, 50(3), 465-476. https://doi. org/10.1111/btp.12531

Petre, C.-A., Tagg, N., Beudels-Jamar, R., Haurez, B., Salah, M., Spetschinsky, V., ... Doucet, J.-L. (2015). Quantity and spatial distribution of seeds dispersed by a western lowland gorilla population in south-east Cameroon. Journal of Tropical Ecology, 31(3), 201-212. https://doi.org/10.1017/S0266467415000073

Petre, C.-A., Tagg, N., Haurez, B., Beudels-Jamar, R., Huynen, M.-C., \& Doucet, J.-L. (2013). Role of the western lowland gorilla (Gorilla gorilla gorilla) in seed dispersal in tropical forests and implications of its decline. Biotechnology, Agronomy and Society and Environment, 17(3), 517-526.

Poulsen, J. R., Clark, C. J., Connor, E. F., \& Smith, T. B. (2002). Differential resource use by primates and hornbills: Implications for seed dispersal. Ecology, 83, 228-240. 
Poulsen, J. R., Clark, C. J., \& Smith, T. B. (2001). Seed dispersal by a diurnal primate community in the Dja Reserve. Cameroon. Journal of Tropical Ecology, 17(6), 787-808. https://doi.org/10.1017/S0266 467401001602

R Core Team (2017). R: A language and environment for statistical computing. Vienna, Austria: R Foundation for Statistical Computing.

Ruiz Pérez, M., Ezzine de Blas, D., Nasi, R., Sayer, J. A., Sassen, M., Angoué, C., ... Yalibanda, Y. (2005). Logging in the Congo Basin: A multi-country characterization of timber companies. Forest Ecology and Management, 214(1-3), 221-236. https://doi.org/10.1016/j.foreco.2005.04.020

Smith, J. R., Bagchi, R., Kettle, C. J., Maycock, C., Khoo, E., \& Ghazoul, J. (2016). Predicting the terminal velocity of dipterocarp fruit. Biotropica, 48(2), 154-158. https://doi.org/10.1111/btp.12316

Swaine, M. D., \& Agyeman, V. K. (2008). Enhanced tree recruitment following logging in two forest reserves in Ghana. Biotropica, 40(3), 370-374. https://doi.org/10.1111/j.1744-7429.2007.00386.x

Tani, N., Tsumura, Y., Fukasawa, K., Kado, T., Taguchi, Y., Lee, S. L., ... Kassim, A. R. (2012). Male fecundity and pollen dispersal in hill dipterocarps: Significance of mass synchronized flowering and implications for conservation. Journal of Ecology, 100(2), 405-415. https:// doi.org/10.1111/j.1365-2745.2011.01929.x

Tosso, F., Cherchye, G., Hardy, O. J., Daïnou, K., Lognay, G., Tagg, N., \& Doucet, J.-L. (2017). Characterization of animal communities involved in seed dispersal and predation of Guibourtia tessmannii (Harms) J.Léonard, a species newly listed on Appendix II of CITES. African Journal of Ecology, 56, 468-476. https://doi.org/10.1111/ aje.12480

Vekemans, X., \& Hardy, O. J. (2004). New insights from fine-scale spatial genetic structure analyses in plant populations. Molecular Ecology, 13(4), 921-935. https://doi.org/10.1046/j.1365-294X.2004.02076.x de, Wasseige, C., Flynn, J., Louppe, D., Hiol Hiol, F., \& Mayaux, P. (2014). The Forests of the Congo Basin - State of the Forest 2013 (Weyrich). Belgium.

Wernsdörfer, H., Caron, H., Gerber, S., Cornu, G., Rossi, V., Mortier, F., \& Gourlet-Fleury, S. (2011). Relationships between demography and gene flow and their importance for the conservation of tree populations in tropical forests under selective felling regimes. Conservation Genetics, 12(1), 15-29. https://doi.org/10.1007/ s10592-009-9983-0

Zhu, P., Ye, W., Cao, H., Wang, Z., \& Saravanan, T. (2013). Preliminary research on pollination and mating system of endangered precious Erythrophleum fordii Oliv. Journal of Tropical and Subtropical Botany, 38-44.

\section{SUPPORTING INFORMATION}

Additional supporting information may be found online in the Supporting Information section at the end of the article.

How to cite this article: Hardy OJ, Delaide B, Hainaut $\mathrm{H}$, et al. Seed and pollen dispersal distances in two African legume timber trees and their reproductive potential under selective logging. Mol Ecol. 2019;00:1-16. https://doi. org/10.1111/mec.15138 